\title{
La construcción de barrios obreros: Una aproximación al debate urbanístico en España, 1881-1907
}

\author{
Raquel Pérez-del Hoyo \\ Departamento de Edificación y Urbanismo - Universidad de Alicante \\ perezdelhoyo@ua.es \\ Clara García-Mayor \\ Departamento de Edificación y Urbanismo - Universidad de Alicante \\ magarma@ua.es \\ Leticia Serrano-Estrada \\ Departamento de Edificación y Urbanismo - Universidad de Alicante \\ leticia.serrano@ua.es
}

La construcción de barrios obreros: una aproximación al debate urbanístico en España, 18811907 (Resumen)

Entre los siglos XIX y XX, se desarrolló en España una intensa polémica sobre la conveniencia o no de construir barrios obreros. La Sociedad Central de Arquitectos -SCA- asumió inicialmente un papel protagonista, incluyendo el debate en el programa de su primer Congreso Nacional y liderándolo durante una década. Conforme avanzó la política social del Estado, el Instituto de Reformas Sociales IRS- confirió al debate una mayor proyección internacional. La revisión y análisis de los argumentos publicados en la Revista de la Sociedad Central de Arquitectos y Resumen de Arquitectura, así como en los informes sobre los Congresos de Casas Baratas compilados en la Preparación de las bases para un Proyecto de Ley de casas para obreros, nos proporciona una clara visión de la evolución del debate, así como de los intereses y preocupaciones de la SCA y el IRS, respectivamente.

Palabras clave: vivienda obrera, barrios obreros, política social, Sociedad Central de Arquitectos, Instituto de Reformas Sociales

The construction of working-class neighbourhoods: an approach to the urban debate in Spain, 1881-1907 (Abstract)

Between the 19th and 20th centuries, a controversial debate has arisen as to whether the development of working-class neighbourhoods in Spain was advisable or not. At the beginning, the Sociedad Central de Arquitectos -SCA- took a leading role. The SCA included the discussion in the first 
National Congress of Architects agenda and led the debate for a decade. As the State's social policy progressed, the Instituto de Reformas Sociales -IRS- gave the debate international exposure. The review and analysis of the arguments published in the magazines Revista de la Sociedad Central de Arquitectos and Resumen de Arquitectura, as well as in the reports on the International Congress of Housing compiled in the Preparación de las bases para un Proyecto de Ley de casas para obreros reports, not only provides a clear overview of the evolution of the debate, but also the SCA and IRS interests and concerns, respectively.

Key words: worker housing, working-class neighbourhoods, social policy, Sociedad Central de Arquitectos, Instituto de Reformas Sociales

El reformista Joaquín Costa, después de visitar la Exposición Universal de París-1867-, concretamente la sección destinada a las «habitaciones de alquiler barato», y conocer los trabajos presentados, no sólo por Francia sino también por Bélgica, Prusia -Alemania-, Holanda o Gran Bretaña, planteó una interesante reflexión: ¿por qué en España los especuladores construían únicamente casas lujosas, expulsando a las clases obreras de las ciudades, sin plantearse siquiera los beneficios que podrían obtener construyendo barrios económicos para personas más modestas? ${ }^{1}$ Barrios obreros como los de Mulhouse, iniciados en 1853 en el Norte de Francia, que habían sido difundidos tempranamente en España por Cerdá ${ }^{2}$ junto con otras distribuciones de ciudades obreras -cerca de Lille o en París-, ya habían procurado importantes beneficios. Era un hecho que, establecer barrios obreros en los centros de trabajo, industriales o agrícolas, además de responder a una demanda social, proporcionaba en Europa grandes rendimientos ${ }^{3}$.

Sin embargo, España no presentó en París ninguna propuesta sobre construcciones económicas ${ }^{4}$, a pesar -en opinión de Costa- de haber podido hacerlo. Este comportamiento manifiesta el desinterés que, en general, mostraron los organismos oficiales, asociaciones y sociedades profesionales relacionadas, sosteniendo que el problema de la vivienda económica no apremiaba en España como en otros países extranjeros ${ }^{5}$. Así, iniciativas pioneras como la construcción de 68 habitaciones obreras en Villalgordo del Júcar, Albacete -junto a la fábrica de papel del industrial Gosálvez-, sólo tuvieron su reconocimiento en la prensa ${ }^{6}$. Por el contrario, estudiosos como Costa, al igual que Cerdá, sí advirtieron el problema, posicionándose en debates que todavía tardarían en producirse más de una década: «iOjalá que las grandes poblaciones se achiquen y repartan luego por los campos (...) que mientras tanto se apague esa sed de construir con lujo para crecidos alquileres (...) y que se construyan barrios obreros $(\ldots) !{ }^{7}$.

1 Costa, 1918, p. 5-8.

2 Véanse los planos de ciudades obreras incluidos en el «Atlas de la Teoría de la construcción de las ciudades» de Cerdá, 1859.

3 Garrido, 1864. En relación a los barrios obreros de Mulhouse y la ciudad de Lila en particular, véanse p. 93 118.

4 Sobre los trabajos presentados por España en la Exposición de París de 1867, véase Lasheras, 2009, p. 476479.

5 De entre las muchas opiniones referentes al asunto, transcribimos como ejemplo la publicada en la Revista de la Exposición Universal de 1867: «No pretendemos nosotros, al ocuparnos con la frecuencia que lo hacemos de la casa del pobre, que nuestros compatriotas se apresuren a surtir las ciudades y los campos de viviendas sanas, baratas y cómodas para uso de las clases trabajadoras; sabemos que esto no han de hacerlo por muchos motivos que no son del momento presente, y estamos convencidos además de que el trasplante en absoluto de las costumbres y objetos de otros países, no es lo más eficaz ni lo más económico para establecer las reformas que necesitamos». Castro, 1867, p. 123.

6 Así lo denunció Costa, 1918, p. 69 y ss.

7 Costa, 1918, p. 71-72. 
Durante el siglo XIX, las ciudades industriales europeas habían crecido enormemente. Primero Londres y otras ciudades británicas, belgas y francesas, después Berlín y otras ciudades alemanas, habían visto incrementada su población y expandirse los suburbios a un ritmo acelerado. El crecimiento urbano se había desarrollado prácticamente por la iniciativa de los agentes privados, centrándose en la demanda solvente, lo que había generado graves problemas de alojamiento para las clases más pobres. 1830 y 1840, habían sido décadas de serios problemas de salud pública y orden social en Gran Bretaña. Así, tras haber vivido el impacto de una primera fase de Revolución industrial, la construcción de colonias obreras había comenzado a explorar nuevas formas de organización espacial y, a partir de 1860, el debate sobre la vivienda popular se había activado en Europa, llegando a las exposiciones universales ${ }^{8}$.

También en España, los principios liberales que se habían ido consolidando en la década de 1850 -la propiedad privada y el mercado libre-, así como el impacto de la desamortización y la venta de gran volumen de edificios, había provocado una profunda transformación social, empeorando las condiciones de vida de las clases más pobres ${ }^{9}$. La industrialización, si bien con menor intensidad en España respecto de otros países europeos, había impulsado el crecimiento económico propiciando la aparición de nuevos grupos sociales: la burguesía urbana y el proletariado industrial, así como una importante densificación y transformación de las ciudades -en algunos casos, hasta un $80 \%$ del caserío de los cascos antiguos entre 1835 y $1865-^{10}$. Así, había comenzado a gestarse un grave problema de desigualdad social -de algún modo subestimado por considerarse menor que en otros países europeos- que empeoró con la crisis financiera de 1866, agravada además por las malas cosechas de los años siguientes. 1860 y 1870 fueron décadas de revolución económica y social. La carestía de alimentos, el hambre y la mortalidad, comenzaron a provocar situaciones, cada vez más extremas, de tensión y conflictividad social ${ }^{11}$.

El trabajo de Costa sobre las habitaciones baratas expuestas en París -un año después del estallido de la crisis en España- no fue publicado hasta entrar el siglo XX. En su lugar, fue el estudio sobre casas económicas del ingeniero José Antonio Rebolledo ${ }^{12}$-elaborado posteriormente- el que se difundió con relativa rapidez -1872-. En el estudio de Rebolledo constaba el listado y descripción actualizado de los barrios obreros y otras iniciativas económicas llevadas a cabo en el extranjero, por lo que tenemos constancia de su conocimiento en España. A pesar de ello, la discusión en torno a la conveniencia o no de construir estos barrios modestos no se inició en el país hasta la siguiente década de los ochenta, coincidiendo con la crisis de Gran Bretaña, Francia y otros países europeos, por la aparición de Alemania como potencia industrial.

A partir de la década de 1880, la generalización de la industrialización, la mecanización, la modernización de la agricultura, el aumento de la migración del campo a las ciudades y el crecimiento de la población, agravaron el problema de la pobreza urbana. El hacinamiento y la carencia de higiene de los barrios populares, las sucesivas epidemias, la escasez de vivienda

\footnotetext{
8 Capel, 2002, 2005 y 2013.

9 Ya en 1853, el Gobernador Pedro de Egaña previno a las provincias de Madrid y Barcelona sobre las pésimas condiciones higiénicas de las viviendas de las clases más pobres y realizó un llamamiento a la acción oficial y particular. Ministerio de la Gobernación, 1853.

10 Capel, 2005, p. 126.

11 Shubert, 1990.

12 Rebolledo, 1872.
} 
económica y los bajos salarios, fueron las consecuencias sociales del sistema capitalista. Las ciudades industriales dejaron de ser habitables y seguras. Así, en España, tras la experiencia del Sexenio Revolucionario -1868-1874- y el impulso de los movimientos sindicales proletarios, el miedo a la presión de las clases obreras y a los enfrentamientos sociales obligó a considerar, como ya se venía haciendo en los vecinos países europeos, el problema de la cuestión social, y muy en particular, el de la pobreza urbana y del alojamiento obrero. También, los higienistas -numerosos médicos, ingenieros y arquitectos-, así como el sector de la burguesía más progresista, comenzaron a implicarse seriamente en los temas de la salubridad de las viviendas ${ }^{13}$.

La Sociedad Central de Arquitectos -en adelante SCA- asumió inicialmente un papel protagonista en el debate español sobre la construcción de barrios obreros, aunque la cuestión no se desenvolvió estrictamente en el ámbito urbanístico. Influyeron otros muchos condicionantes sociales, políticos, económicos, sanitarios, ideológicos e incluso morales; cualquier orden establecido en la ciudad tradicional se vio profundamente afectado por los rápidos cambios derivados de los procesos industriales. Además, el discurso higienista, centrado en el estudio de las condiciones mínimas que debían cumplir las viviendas iluminación, ventilación-, fue relegando a un segundo plano la problemática de su distribución espacial. Posteriormente, en 1903, la creación del Instituto de Reformas Sociales -en adelante IRS- significó la institucionalización de la política social en España, favoreciendo la internacionalización de sus debates inherentes, entre éstos el de los barrios obreros $^{14}$.

En el contexto descrito, el objeto de este artículo es aportar una visión crítica, clara y progresiva de la evolución del debate: desde su primer planteamiento, en el ámbito nacional, por iniciativa de la SCA, en 1881; hasta que comenzaron a sumarse al discurso las primeras propuestas de ciudades jardín, tras su presentación en el Congreso Internacional de Casas Baratas de Londres, en 1907, al que asistieron representantes del IRS. Para ello, la revisión y el análisis de los argumentos utilizados en la Revista de la Sociedad Central de Arquitectos y en Resumen de Arquitectura, así como en los informes sobre los Congresos de Casas Baratas compilados en la Preparación de las bases para un Proyecto de Ley de casas para obreros, nos ofrece una lectura amplia y comprensiva de la complejidad del asunto, a la vez que de los intereses de la SCA y preocupaciones del IRS, respectivamente.

\section{Planteamiento del debate: primer Congreso Nacional de Arquitectos, 1881}

El debate sobre la conveniencia de la construcción de barrios obreros frente a otros sistemas mixtos de estratificación social se produjo en España, con cierto retraso, a partir del primer Congreso Nacional de Arquitectos celebrado en Madrid, por iniciativa de la SCA, en mayo de 1881. Más de un centenar de arquitectos españoles discutieron entonces sobre el problema de la vivienda obrera, pero no sólo para denunciar y tratar de mejorar sus lamentables condiciones higiénicas. La importancia del debate se centró en esclarecer cómo su construcción podría llegar a influir sobre la forma urbana y su organización social y, en este sentido, en si resultaría más apropiado, de acuerdo con el contexto social, construir barrios

13 Capel, 2002, 2005 y 2013.

14 Para conocer los principales estudios desarrollados sobre vivienda obrera y las primeras actuaciones realizadas entre los siglos XIX y XX, véase el estado del arte elaborado por Tatjer, 2005. 
aislados o integrados en las ciudades ${ }^{15}$. Se trató, en definitiva, de debatir sobre «la estructura física de las sociedades» ${ }^{16}$.

Para entender el modo en que se desarrolló el interesante debate conviene, en gran medida, conocer las circunstancias que a priori lo condicionaron. La extraordinaria transformación de la ciudad industrial, con la reforma interior de los cascos urbanos y la expansión de nuevos e higiénicos barrios de ensanche, había precisado una importante inversión económica. La apertura de nuevas calles, las expropiaciones y derribos, la instalación de redes de agua, saneamiento, gas o electricidad, así como de transporte, además de la creación de equipamientos y espacios libres para la nueva burguesía, había conllevado el endeudamiento de las administraciones locales y hasta su cuestionamiento mediático. En esta coyuntura, la vivienda había surgido como una posible inversión y la industria privada de la producción de viviendas, por su rentabilidad, constituía uno de los mayores apoyos para seguir financiando la ciudad burguesa. Así, la expectativa de beneficio determinaba la actuación de los promotores de la construcción de viviendas, tanto para la venta como para el alquiler. No interesaba, por tanto, atender la demanda de las clases más pobres, por muy importante que fuera, sino únicamente la demanda solvente de la burguesía y las clases medias ${ }^{17}$.

En este contexto, realmente eran otras -y no el problema de la vivienda obrera- las cuestiones que preocupaban a la SCA: por un lado, las relativas al «estilo moderno» en la Arquitectura; y por otro lado, las que afectaban a la organización de la profesión de Arquitecto. Estos fueron, por tanto, los principales foros de discusión propuestos para el Congreso, los que afectaban a la imagen de la ciudad burguesa y al propio colectivo de arquitectos. Si bien, dados los profundos cambios sociales que estaban ocurriendo en el país, el debate sobre la construcción de barrios obreros de ningún modo podía quedar excluido del programa, sin duda por el manifiesto retraso en producirse con respecto a Europa, pero sobre todo por la dramática escasez real de viviendas económicas y su consecuente reclamo social. Sin embargo, la misma razón que en principio favoreció el debate: la circunstancia de tratarse de un problema social, también provocó después el desinterés de un gran número de arquitectos, llegándose a desaconsejar enviar ponencias sobre el tema, como en el caso de la Asociación de Arquitectos de Cataluña, por considerarlo más propio del discurso político que del interés estrictamente profesional. Verdaderamente, el debate no sólo adquirió una importante connotación ideológica. La SCA, representada en la figura de su vicepresidente Lorenzo Álvarez Capra, optó por posicionarse frente a la cuestión de forma taxativa, evidenciando las sustanciales diferencias de opinión que se venían gestando en el mismo seno de la $\mathrm{SCA}^{18}$.

Respondiendo al título: «Dada la organización actual de la sociedad, ¿es o no conveniente la construcción de barrios obreros?», Álvarez Capra se pronunció en contra de cualquier forma de agrupación residencial concebida para alojar exclusivamente a las clases trabajadoras. La defensa de la idea de ciudad tradicional como espacio mixto de integración social y, por tanto, de encuentro y convivencia de las diferentes clases sociales, constituyó el argumento fundamental del discurso, aunque no en favor de un derecho igualitario. El trasfondo paternalista y el sentimiento de cierta superioridad moral, a la vez que el miedo a perder de algún modo el control social ante la amenaza de una posible emancipación obrera,

15 Como apunta Martínez, 2005, interesantes referencias a este Congreso pueden encontrarse en Barreiro, 1992 , p. 24 y ss.; Blat, 2000, p. 85 y ss.; y Sambricio, 2003, p. 35 y ss. Asimismo pueden consultarse las Actas del Congreso: Sociedad Central de Arquitectos, 1883b. Véase también Isac, 1982.

16 Capel, 1987, p. 42 y ss.

17 Capel, 2002, 2005 y 2013.

18 Granell y Ramon, 2012, p. 41-52. 
determinaron el posicionamiento de la SCA: «al obrero es conveniente albergarle en nuestra propia casa, tenerle al lado nuestro para socorrerle en sus enfermedades; y la sociedad no se arrepentirá de ello, pues en caso de accidente es inseparable, y tiene probado que da su vida por el que le tiende su mano» ${ }^{19}$.

La convivencia de clases en los distintos barrios de la ciudad evitaba, según Álvarez Capra, la formación de núcleos aislados de desorden o infección, pero precisaba asumir un rígido sistema de organización social basado en la estricta diferenciación vertical o clasificación por pisos en los edificios, requería pues de un orden que entendiera como natural que los sótanos y áticos fueran ocupados por los obreros, las plantas primeras o principales por la burguesía, y los segundos y terceros pisos por las clases medias. Se trataba del más que ensayado sistema mixto caricaturizado por Bertall en el contexto parisino 20, un sistema que en Europa ya había sido prácticamente desechado, pero la SCA, con su atención fijada en otros intereses, optó por posicionarse en esta línea más conservadora y en contra de las tendencias europeas del momento ${ }^{21}$.

El sistema de estratificación social se había difundido en España desde finales del siglo XVIII, y desde mediados del XIX, se había planteado como un modelo beneficioso para la convivencia de los grupos sociales. Evidentemente, el sistema ofrecía además un importante beneficio económico, justificando el aumento del número de plantas en los edificios y la conversión de los sotabancos en viviendas alquilables, pero no existía un consenso entre los propietarios del suelo. Prescindir de las clases más pobres también aumentaba el valor de los inmuebles. La alternativa se basaba en sustituir la segregación vertical por la segregación horizontal -como ya se venía haciendo en los edificios diferenciando entre viviendas exteriores e interiores, e incorporando incluso accesos separados-, y consistía en la construcción de barrios obreros segregados, con viviendas económicas e higiénicas, expulsando así a las clases pobres de los barrios burgueses. Todo ello, aprovechando la denuncia de los críticos sociales sobre el pésimo estado de las viviendas modestas en las ciudades, aunque curiosamente esta denuncia fuera en contra de los mismos inversores ${ }^{22}$.

No es que faltaran en España antecedentes críticos sobre el tema. El mismo Ildefonso Cerdá ya había denunciado el uso de ciertas hipocresías, tanto en la práctica del leguaje urbano, para disimular defectos como los provocados por la excesiva superposición de pisos en los edificios; como a la hora de interpretar la composición formal de los inmuebles, defendiendo intenciones normativas o estableciendo jerarquías sociales donde en origen sólo primaron principios constructivos. Confundir terceros o cuartos pisos con primeros, elevados sobre bajos, entreplantas y principales, permitía a los propietarios del suelo especular construyendo edificios de cuatro o cinco pisos cuando realmente contenían hasta diez, incluyendo una o dos plantas de ático, aprovechando incluso los espacios de cubierta, además de una o dos de sótano. Verdaderamente, resultaba muy pesado acceder a los pisos altos, teniendo además menos altura libre conforme al menor espesor de los muros. También los cerramientos de fachada disminuían su grueso de acuerdo con la carga soportada, menor en las plantas superiores, aumentando así su retranqueo con la altura, consiguiéndose una reducción adicional de esfuerzos con el acortamiento de los vuelos. Sin embargo, al igual que la normativa convino aclarar que el retranqueo de las fachadas se había producido

19 Granell y Ramon, 2012, p. 51.

20 Véase la viñeta titulada: Coupe d'une maison parisienne le ler janvier 1845, cinq étages du monde parisien en Lavallée, 1845-1846, p. 27. O la misma ilustración en Texier, 1852-1853, p. 65.

21 Yeste, 2003, p. 553-554.

22 Capel, 2005, p. 155 y ss. 
intencionadamente en beneficio de la calle, la importancia del balcón terminó representando una mayor jerarquía en la vivienda. De algún modo, reflejando esa cierta hipocresía denunciada por Cerdá, la vanidad y el interés tanto de administraciones como de propietarios o inquilinos fue perfilando el sistema mixto de estratificación social defendido por la SCA, sin especificar nunca qué otros sistemas o modelos concretos se rechazaban ${ }^{23}$.

En oposición, el discurso de Mariano Belmás Estrada, secretario de la SCA, sí trató de precisar la definición de un posible modelo alternativo de barrio obrero y aunque todavía no se había teorizado el concepto de ciudad jardín, lo concibió como tal 24 . No se trataba de construir un gran complejo aislado de viviendas de alquiler ni de mantener los suburbios que habían crecido sin control, añadidos a la ciudad, amontonando a la clase obrera, posibles focos de desorden o infección como denunciaba la SCA; sino de formar grupos no muy numerosos de casas, con jardín en su caso, accesibles para las gentes modestas, bien planificados y adecuadamente distribuidos en la población: «Si por barrios para obreros se entienden superficies en distintos puntos de las poblaciones, sobre las cuales se asientan casas con más o menos jardín para familias modestas, benditos sean los barrios para obreros, porque realizan un bello ideal» ${ }^{25}$.

La propuesta de Belmás, quien -el mismo año, 1881- se trasladó a Inglaterra para estudiar la vivienda social desde perspectivas higienistas, rompía radicalmente con la serie de dependencias y categorías implícitas en el sistema mixto y este hecho, por su trasfondo económico y social, constituía sin duda el principal problema ${ }^{26}$. Para la sociedad del momento, no era posible aceptar que los barrios económicos pudieran ser al mismo tiempo de calidad porque los barrios de esta naturaleza suponían para las clases pudientes la «compensación justísima y bien merecida de las privaciones sin cuento que las urbanizaciones condensadas imponen a sus moradores». Ya lo había anticipado Cerdá, la propuesta planteaba un proceder lógico de expansión urbana pero sólo en los casos en que la densidad suponía un problema, porque nadie buscaría en las afueras la amplitud y el espacio que pudiera tener en la ciudad y, en la situación contraria, difícilmente la población modesta tendría acceso a esas comodidades $^{27}$.

La conveniencia de la construcción de barrios para las clases de mayor poder adquisitivo no era, pues, una cuestión discutible, pero sí cuando se trataba de construirlos para las clases obreras. Por ello, se concebían de antemano caros y elegantes, de moderna arquitectura, amplios jardines y perspectivas, de sobrada holgura, comodidad y bienestar, dotados de un aislamiento propio, sobre todo separados del hacinado casco urbano y construidos de acuerdo con las mejores condiciones higiénicas, sin caber la posibilidad de mejorar su economía para permitir el acceso a las clases menos pudientes; una concepción cuanto menos paradójica porque el argumento que solía garantizar su viabilidad no era otro sino el de pretender aliviar, precisamente, el problema de la vivienda obrera, llegando incluso a cuestionar el modelo mixto. Casos como la construcción del barrio del Nuevo Carabanchel en Madrid $^{28}$ o de Benalúa en Alicante ${ }^{29}$, ilustran sobradamente esta circunstancia.

23 Sobre la superposición de plantas en los edificios, véase Cerdá, 1867, p. 586-588; sobre la altura de los pisos, p. 449-450; sobre el grosor y retranqueo de los muros y voladizos, p. 328-330.

24 Granell y Ramon, 2012, p. 50-51. Véase también: Belmás, 1881, 1882 y 1883; Alonso, 1982.

25 Yeste, 2003, p. 554.

26 Como indica Priego, 2010, p. 193, Belmás debe considerarse parte de la generación que renovó la Sociedad Central de Arquitectos.

27 Cerdá, 1867 , p. 236-237.

28 Del siguiente modo describía la empresa constructora su actuación: «Un pueblo, pues, construido con todos los adelantos que las sociedades modernas han impreso a los edificios destinados a servir de habitación al 
De cualquier otro modo se hubiera percibido invertido el orden social. En este contexto debe entenderse la posición adoptada por la SCA, en la inercia o conveniencia de mantener el modelo heredado de ciudad, de espaldas a la realidad producida por el rápido y descontrolado crecimiento, sin abordar verdaderamente el debate urbanístico -además de económico, social y político- que implicaba su cuestionamiento ${ }^{30}$.

\section{Desarrollo del discurso: la Revista de la Sociedad Central de Arquitectos, 1882-1890}

La postura conservadora expuesta por la SCA en su Congreso, entre el desinterés o el rechazo de las corrientes europeas, llegando a anteponer la urgencia de reformar la ciudad para embellecerla a la necesidad de reorientar los esfuerzos en el logro de una mayor cohesión social, también tuvo su reflejo en el periódico órgano oficial de la SCA, denominado Revista de la Sociedad Central de Arquitectos, del que el propio Belmás dimitió como director, además de como secretario de la misma SCA, coincidiendo con la elección como presidente de José María Aguilar y Vela, representante de las posturas más conservadoras ${ }^{31}$.

Tras la celebración del primer Congreso Nacional de Arquitectos, el debate sobre la conveniencia de la construcción de barrios obreros quedó completamente apartado. Las Actas de las sesiones no fueron publicadas hasta transcurrir dos años, convirtiéndose el periódico de la SCA en el principal vehículo para difundir sus intereses. Los artículos publicados durante esta etapa, al igual que las sesiones del Congreso, desarrollaron principalmente asuntos sobre el estilo, el embellecimiento y la profesión, aludiendo a la necesidad de reformar la ciudad pero sólo en su apariencia estética ${ }^{32}$. No fue hasta finalizar el año 1882 cuando, de forma anónima, volvió a tratarse el tema de la vivienda obrera, reivindicando la cuestión social como principio inseparable de la reforma más allá de la apertura o ampliación de calles, plazas, o construcción de monumentos ${ }^{33}$.

\footnotetext{
hombre; pueblo formado de hoteles, en los que alternen desde el más modesto al más suntuoso, relativamente hablando, dentro de las condiciones marcadas por la Sociedad...». La casa más económica ascendía a 5.000 pesetas. Constructora del Nuevo Carabanchel, 1895, p. 9.

29 Así constaba en los informes del Instituto de Reformas Sociales: «En 1882 se fundó una Sociedad anónima titulada Los Diez Amigos para la construcción de 208 casas de dos plantas en el barrio de Benalúa, entre ellas algunas de un valor de 2.000 pesetas, para que pudiesen ser alquiladas por los obreros. Más tarde se acordó que las casas fueran de un piso más, aumentándolas en comodidades y elevando su presupuesto a 10.000 pesetas; $y$ como, aunque las casas quintuplicaban su valor $y$ eran capaces para varias familias, se necesitaba mucho más tiempo para amortizarle, la clase obrera se retrajo de adquirirlas». Instituto de Reformas Sociales, 2010, p. 479. Véase también Pérez y Gutiérrez, 2013.

30 Capel, 1983.

31 En 1874, se creó el Boletín de la Sociedad Central de Arquitectos, la primera publicación especializada en Arquitectura en España. En 1876, se convirtió en la Revista de la Sociedad Central de Arquitectos, pasando a denominarse, a partir de 1878, Revista de la Arquitectura nacional y extranjera. Colegio Oficial de Arquitectos de Madrid, 2006-2007. En marzo de 1882, comenzó su tercera etapa volviendo a la denominación Revista de la Sociedad Central de Arquitectos. Se publicaron preferentemente documentos oficiales de la Sociedad y disposiciones relacionadas con la profesión — -vacantes, concursos, subastas, normas, reglamentos-, otros datos prácticos de interés — precios, materiales, fórmulas-, estudios de monumentos, informaciones de conferencias, exposiciones, así como otras noticias y consultas. Sociedad Central de Arquitectos, 1882, p. 1-2. 32 Sobre cuestiones de estilo, véase Lázaro, 1882. Sobre reforma y embellecimiento de la ciudad, véase Concha, 1882 y 1883.

33 Sociedad Central de Arquitectos, 1882, p. 215-216 y 223-224. Artículo sobre «la cuestión obrera» reproducido del periódico El Imparcial.
} 
La situación de las habitaciones de las familias obreras o modestas volvió a ser entonces duramente denunciada, y no sólo por su consabida precariedad higiénica e influencia en las tasas de mortalidad, sino por venirse favoreciendo cada vez más su exclusión del modelo de organización social. De forma inconsciente, o no, con la atención puesta en otros asuntos, su inamovible postura y el desinterés mostrado en general hacia el verdadero problema de la vivienda, la SCA estaba participando en el desarrollo de un modelo de ciudad en el que ni siquiera tenía ya cabida el sistema de estratificación social que teóricamente defendía. Precisaba, pues, recuperar el discurso mantenido en el Congreso de Madrid, para lo que era necesario reconocer primero la delicada situación a que se había expuesto la cuestión del alojamiento obrero.

La habitación económica estaba siendo violentamente expulsada del mercado en que se había convertido el modelo de ciudad: «Pero ni aun en esas boardillas, ni aun en esas casas de vecindad se albergarán dentro de poco los necesitados. La construcción moderna todo lo invade repeliendo las viviendas baratas (...) El obrero entonces tiene que buscar hogar en los barrios extremos y hasta en los pueblos inmediatos ${ }^{34}$. Aunque, no por ello debía defenderse la conveniencia de construir barrios económicos. En opinión de la SCA, concurrían en su contra dos razones fundamentales: la importancia de mantener la proximidad entre las habitaciones de los operarios y sus lugares de trabajo, evitando así perder horas de descanso en desplazamientos; y la necesidad de proponer soluciones que, lejos de la utopía, resultaran coherentes tanto con los comportamientos previsibles del mercado como con los intereses del propio orden social establecido.

No es que la SCA no admitiera la bondad de las barriadas económicas, tanto de las modestas ensayadas incluso en España como de las grandes actuaciones más que reconocidas en Europa, pero anteponía el inconveniente de tenerse que construir en terrenos alejados de los núcleos urbanos: «En las grandes ciudades no es posible hacer esas bonitas barriadas de obreros que levantó la casa Dreyfus en Mulhouse, cercadas de jardines y con vivienda independiente de un solo piso para cada familia de obrero» ${ }^{35}$. Tampoco es que no elogiara las iniciativas que proponían convertir a los obreros en propietarios de sus casas, si bien, no concebía creer en la viabilidad de estas propuestas. En su opinión, la construcción de barrios obreros no era factible, sobre todo porque «cuando el valor del terreno lo absorbe todo, ya no se debe pensar en barrios especiales económicos» ${ }^{36}$.

El artículo difundido en la Revista de la SCA también dejaba entrever, recuperando el argumento defendido en el Congreso, otras razones de intención más ideológica o moral. Los barrios obreros ofrecían además «el inconveniente de reproducir aquellas antiguas segregaciones que dentro de una misma ciudad mantenían las clases sociales separadas, y, por consiguiente, concentrando cada una de ellas en una especie de demarcación con fronteras que daban aliento a los odios y rivalidades». Sin embargo, más allá de pretender con la supuesta integración el beneficio de la sociedad en su conjunto, afirmaciones como «es altamente ventajoso para las clases que necesitan servicios, tener cerca a los que pueden prestarlos», desvelaban una segunda lectura muy cuestionable del asunto ${ }^{37}$.

En cualquier caso, el posicionamiento de la SCA seguía siendo taxativo: «No cabe, por consiguiente, otra solución para las ciudades populosas que la de construcciones mixtas en 
que los pisos altos estén distribuidos en viviendas pequeñas o la de edificios especiales diseminados, en que todo esté distribuido de modo que las familias obreras de buenas costumbres puedan tener espacio, independencia, luz, aire puro y comodidad por un alquiler moderado» 38. La SCA seguía pues defendiendo el sistema mixto de estratificación social pero también había aceptado el conocido sistema de casas de vecindad, aunque apuntara a la idea supuestamente rechazada de mantener las clases sociales separadas en edificios especiales segregados. La cuestión se justificaba destacando la ventaja de estas edificaciones de uno u otro sistema- respecto de las construcciones aisladas, sobre todo para disponer de servicios generales como calefacción, agua, limpieza, facilitando incluso la cooperación alimenticia, como indicaba el estudio de modelos extranjeros ${ }^{39}$.

\section{Paréntesis en el discurso de la distribución espacial de la habitación económica}

Al comenzar el año 1883, el debate sobre la distribución espacial de la vivienda obrera volvió a ser olvidado. Sería otro el discurso ampliamente desarrollado en la Europa de finales del siglo XIX. La acción del capitalismo conllevó elevadísimos costes sociales, obligando a las administraciones a tomar el protagonismo e impulsar una creciente intervención pública. El más que esperado debate sobre la intervención de los poderes públicos en el problema de la vivienda, sobre si el deber de procurar habitaciones cómodas y sanas correspondía al Estado o a los municipios y si debían éstos convertirse en constructores o estimular la empresa privada, culminaría con la ansiada aprobación de las primeras leyes europeas de casas baratas postergando de algún modo la reflexión de otros debates como el propio sobre la conveniencia de construir o no barrios obreros.

En España, la SCA también se sumó a este debate recurrente en la Europa desarrollada aunque como mera espectadora, limitándose a informar, a través de su Revista, sobre las iniciativas surgidas en los países más avanzados -y afectados por el rápido desarrollo industrial de Alemania-: sobre la propuesta de París, en la línea de facilitar el crédito, asegurando además la disminución o exención de cargas o impuestos; o de Inglaterra, apostando por proteger al inquilino, exigiendo al propietario la garantía de mantener unas mínimas condiciones económicas e higiénicas. De este modo, el debate sobre la vivienda fue comprendiéndose progresivamente en su sentido más amplio, sin rechazar de antemano ninguna forma de organización social posible. Los planteamientos de París o de Inglaterra dejaban entrever esta circunstancia, al considerar igualmente válidas, tanto las propuestas que mantenían o desarrollaban sistemas mixtos como las que apostaban por planificar o reformar barrios obreros completos ${ }^{40}$.

\footnotetext{
38 Sociedad Central de Arquitectos, 1882, p. 224.

39 Se refería expresamente al industrial Godin y la construcción del Familisterio en Guisa —Francia—, con cuatro plantas de altura, como posible modelo susceptible de ser modificado.

40 En relación a París, se transcribió un artículo sobre «la habitación barata» del periódico El Imparcial: Sociedad Central de Arquitectos, 1883a, p. 96. Respecto a Londres, véase la referencia a «casas para obreros»: Sociedad Central de Arquitectos, 1883a, p. 270-271. En el caso de París, se favorecía tanto a los propietarios que al construir una casa destinaran la mitad de su superficie a habitaciones de alquiler asequible; como a los particulares que levantaran sus propias casas de valor modesto, pudiendo asociarse varias familias y recurrir incluso a empresas; así como a los constructores, jefes de fábricas o sociedades que edificaran habitaciones, en alquiler o en propiedad, para ser pagadas en plazos suficientemente prorrogados. En el caso de Inglaterra, se exigían las mismas responsabilidades a todo tipo de propietario, tanto de edificios como de barrios enteros.
} 
Por su parte, la SCA no llegó a mostrar interés en el asunto hasta finalizar el año 1883. Fue con motivo de la creación de la primera institución estatal para llevar a cabo programas sociales en España: una Comisión para el estudio de la mejora y bienestar de las clases obreras, con el objeto, entre otros propósitos, de recabar información sobre los temas de «habitaciones de obreros; higiene de los barrios habitados por las clases trabajadoras; reformas en la legislación municipal y medios que puedan emplearse para estimular la construcción de habitaciones baratas y sanas para las clases obreras ${ }^{41}$. Sin duda, se trató de un interés exclusivamente profesional, con la única pretensión de reivindicar para los arquitectos sus teóricas competencias: «A nadie se oculta que este particular cae enteramente bajo la jurisdicción profesional del arquitecto, y nos obliga por tanto a seguir de cerca los trabajos de la Comisión dicha» ${ }^{42}$.

La indiferencia de la SCA por el verdadero problema de la vivienda obrera resultaba cada vez más evidente. Valga como ejemplo la forma de referir las construcciones económicas que Belmás recién había presentado en la Exposición Nacional de Minería -Madrid, 1883-: «Como las casas económicas del Sr. Belmás son ya tan conocidas, y nada ofrecen de notable desde el punto de vista artístico, no tenemos por qué ocuparnos de ellas en este lugar» ${ }^{43}$; o la manera absoluta de ignorar, desde 1882, los innovadores planteamientos de Arturo Soria y Mata sobre la Ciudad Lineal como estrategia de crecimiento y modelo alternativo de ciudad extrarradio -campo-ciudad-, incidiendo en los valores de cohesión social, utilidad, sencillez y economía, así como en la importancia del desarrollo de infraestructuras y comunicaciones: «Es menester que cada familia tenga su hogar completamente separado de los demás; un pedazo de terreno, por pequeño que sea, exclusivamente suyo, su parte de sol y de aire; vivan juntos el palacio del poderoso (...), y la cabaña del pobre (...); pero no que vivan superpuestos» ${ }^{44}$.

Más allá de preocuparse por la presencia de los arquitectos en la serie de comisiones provinciales y locales que debían colaborar con la central de Madrid en informar sobre el estado y necesidad de la clase obrera, la Revista de la Sociedad Central de Arquitectos difundió únicamente actuaciones puntuales muy concretas: la iniciativa de la sociedad Los Diez Amigos para construir 208 casas formando el barrio de Benalúa en Alicante; la construcción de un cuarto grupo de 17 casas para obreros, sumando un total de 51 viviendas, en la ya conocida como calle de la Caridad de Madrid, por iniciativa de La Constructora Benéfica; o los proyectos de cuatro barriadas para 500 vecinos en Valencia; o de un gran barrio en la parte de Levante en Elche ${ }^{45}$. De este modo, la SCA soslayó el asunto durante un trienio hasta optar finalmente por evitar realizar cualquier comentario. Incluso, llegó a celebrarse el segundo Congreso Nacional de Arquitectos, coincidiendo con la Exposición Universal de Barcelona, en 1888, sin tratar el asunto.

Transcurriría casi un lustro para que la SCA volviera a opinar sobre el tema, aunque de nuevo intervendría motivada por el interés profesional. La Comisión creada, en 1883, para el estudio de las cuestiones obreras fue ampliada y reorganizada, en 1890, en la Comisión de Reformas Sociales -en adelante $\mathrm{CRS}_{-}{ }^{46}$ olvidando entre sus miembros a los arquitectos, exclusión

41 Ministerio de la Gobernación, 1883.

42 Sociedad Central de Arquitectos, 1883a, p. 288. Véase el apartado de noticias.

43 Repullés, 1883, p. 281.

44 Ramón, 1993, p. 132. Véanse también las referencias a Soria, 1882 y 1883, en Terán, 1964 y 1968 ; Navascués, 1969 y 1979; y Sambricio, 1992.

45 Véanse los apartados de noticias: sobre Alicante, Sociedad Central de Arquitectos, 1884, p. 8 y 1885, p. 152; sobre Madrid, 1884, p. 223; sobre Valencia, 1885, p. 216; y sobre Elche, 1886, p. 236.

46 Ministerio de la Gobernación, 1890. 
denunciable, en palabras de la SCA, «cuando la naturaleza de algunas de las cuestiones en que está llamada a entender aquella Comisión, son de la exclusiva competencia de nuestra profesión» ${ }^{47}$. Por ello, bajo la presidencia de Higinio Cachavera y Pascual, se acordó dirigir una exposición al Ministerio de la Gobernación, resultando un documento fundamental para entender el posicionamiento de la SCA transcurrida casi una década desde la celebración del primer Congreso de Madrid. Además del innegable interés profesional, volvía a constatarse un importante trasfondo ideológico y moral, entre la manipulación y el paternalismo, muy pendiente de la dimensión que iba adquiriendo la cuestión social obrera. La nueva estrategia consistía en erigir a la SCA como intermediaria en representación del numeroso conjunto de trabajadores de la construcción: «Colocada, además, nuestra clase al frente de esa gran masa de obreros, (...) conoce sus necesidades y aspiraciones, sigue su vida cotidiana y ejerce sobre ella gran influencia, pudiendo por lo tanto ser factor importantísimo en los estudios que van a ser objeto de los futuros acuerdos de la Comisión» ${ }^{48}$.

Así, ocupada en consolidar la organización de la profesión en el país, la SCA fue distanciándose del progreso de la cuestión obrera en Europa. De hecho, el último avance publicado en su Revista fue la propuesta del proyecto de ley sobre viviendas para obreros resultado del trabajo realizado por la Comisión Real para la vivienda de las clases trabajadoras creada en Inglaterra, en $1884^{49}$. Después, se crearon otras comisiones como las de Alemania -1885- o Bélgica -1887- y comenzaron a aprobarse las que pueden considerarse primeras leyes de casas baratas, primero en Bélgica -1889- o Inglaterra -1890- y después en otros países como Austria -1892-, Francia -1894- o Alemania $-1895-^{50}$, pero ninguno de estos asuntos fue publicado en la Revista de la SCA. Indudablemente, el hecho de que en España los gobiernos no apoyaran la difusión de los trabajos realizados por su Comisión, aun habiéndose creado ésta junto con la francesa antes que en ningún otro país, debió favorecer o por lo menos justificar la actuación de la SCA. Los primeros resultados de la Comisión española, que no tuvo competencias para desarrollar proyectos de ley hasta su reorganización en la CRS, no comenzaron a publicarse hasta $1889^{51}$. A partir de entonces, el debate higienista sobre la ciudad industrial derivó en dos importantes discursos que introdujeron nuevos argumentos: la propiedad obrera y la separación de clases. Desde estas perspectivas, la creación de casas o barrios obreros ya no sólo serviría para mejorar las condiciones higiénicas de las poblaciones, convertir al obrero en propietario, integrando o segregando espacialmente su vivienda, constituiría una nueva estrategia de la burguesía para seguir ejerciendo el control $\operatorname{social}^{52}$.

La publicación de los trabajos de la CRS, coincidió con la celebración del primer Congreso Internacional de Casas Baratas, la primera de una serie de reuniones orientadas básicamente a respaldar las posturas de los diferentes países anfitriones y sus respectivos proyectos de ley ${ }^{53}$. En los Congresos de Casas Baratas no se debatió inicialmente sobre la construcción de barrios obreros, la discusión sobre la intervención de los poderes públicos eclipsó el resto de debates, pero sí surgieron ciertos temas que de algún modo aludieron al asunto. En el primer Congreso de Habitations à bon marché, que tuvo lugar en París al tiempo que fue aprobada la Ley belga

47 Véase el Acta de la Junta de Gobierno celebrada el 16 de mayo de 1890. Sociedad Central de Arquitectos, 1890, p. 194.

48 Cachavera y Lampérez, 1890, p. 195.

49 Sociedad Central de Arquitectos, 1885, p. 183. Véase la referencia a «viviendas de obreros».

50 Hall, 1996, p. 24-43.

51 En total se publicaron cinco tomos, uno por año, desde 1889 hasta 1893 . Véase Calle, 1984, p. 36.

52 De ahí el rechazo de los representantes socialistas participantes en la Comisión hacia los barrios obreros. Véanse Buj, 1994, Castrillo, 2001 y Martínez, 2005.

53 Castrillo, 2003, p. 17-21. 
-1889-, se denunció cómo la destrucción completa de barriadas existentes con el propósito de sanear o embellecer la ciudad, complicaba todavía más el problema de la vivienda. En los siguientes Congresos, celebrados en Amberes -1894- y Burdeos -1895- coincidiendo con la aprobación de las Leyes francesa y alemana respectivamente, tampoco hubo pronunciamientos a favor o en contra de la construcción de barrios económicos, aunque sí se discutió sobre el posicionamiento de Alemania frente al denominado «alojamiento profesional». Realmente, interesaba debatir sobre si debía el Estado intervenir como patrono defendiendo a sus trabajadores, pero a la vez se retomó el discurso sobre cómo ciertos barrios podían tener su justificación en la industria: «Si instala sus talleres en despoblado, tiene que hacer casas para obreros (...) y las casas, en este caso, forman parte del mecanismo industrial» ${ }^{54}$.

A partir de 1890, la recuperación económica se produjo a un ritmo moderado, teniendo en cuenta las circunstancias propias de cada país. Pero, en el caso de Alemania, el problema de la vivienda llegó a ser extremo. La industrialización en Alemania alcanzó su desarrollo más intenso y acelerado, convirtiéndose en la primera potencia tecnológica de Europa y de los mercados mundiales. Las ciudades más importantes se convirtieron en focos de concentración, pasando a desempeñar un papel fundamental en el sistema económico. La extrema rapidez con que se produjo la urbanización agravó de manera dramática los problemas ambientales, higiénicos y sociales. El proletariado urbano era la clase más numerosa en las ciudades alemanas y a este grupo se sumaba una compleja burguesía de pequeños empleados y funcionarios -trabajadores del Estado a los que se aludía en el Congreso de Burdeos-, y de comerciantes y artesanos, de diferentes ideologías. A todos afectaban los problemas de la ciudad y las espantosas densidades alcanzadas con la extendida construcción de bloques de alquiler -o cuarteles-. Además, a pesar de estas densidades, la falta de vivienda y los altísimos alquileres eran problemas crónicos, fundamentalmente por el elevado precio del suelo. Así, las ciudades fueron escenario de profundas tensiones sociales, manifestaciones y revueltas populares, cobrando importancia los movimientos obreros y las organizaciones sindicales. La alerta de las clases dirigentes y la lucha contra el socialismo, para mantener el orden político y sociocultural tradicional, se tradujo en una intervención pública masiva, consentida por el sector privado por impulsar el máximo desarrollo económico y productivo. El Estado apoyaba el acceso al crédito y proporcionaba las infraestructuras necesarias para convertir las ciudades en eficaces máquinas productivas ${ }^{55}$.

El desarrollo tecnológico y de los medios de transporte, y en particular la experiencia alemana, afectó sustancialmente el debate urbanístico, comenzando a plantearse cada vez más necesaria una intervención pública en la ciudad, así como el empleo de nuevos instrumentos para el control y la reforma: para la zonificación de los usos y las actividades -residencial, comercial, industrial- y para la distribución de los distintos grupos de población en la ciudad.

\section{El resurgir del debate con Resumen de Arquitectura, 1891-1900}

Con la entrada en la última década del siglo XIX, la SCA inició un nuevo proyecto: la revista Resumen de Arquitectura. A partir de entonces, la Revista de la Sociedad Central de

54 Sobre el primer Congreso de París, véase Instituto de Reformas Sociales, 1910, p. 23. Sobre los siguientes Congresos de Amberes y Burdeos, p. 97-98.

55 Mancuso, 1980. Piccinato, 1993. 
Arquitectos publicó únicamente actas oficiales, trabajos realizados por la SCA y disposiciones relacionadas con la profesión de Arquitecto ${ }^{56}$.

La naciente publicación no tardó en servir de medio para difundir, como su antecesora, los intereses de la SCA, manteniendo su postura contraria a la construcción de nuevos barrios económicos, aunque con la excepción de los denominados industriales. Cerdá ya había estudiado estos barrios industriales como uno de los tipos posibles de suburbios ${ }^{57}$, si bien ahora -distanciándose de algún modo de la experiencia alemana- se consideraban casos especiales separados de la problemática general: «En buen hora que se procure la construcción de barrios para obreros en aquellos puntos donde forzosamente ha de establecerse una industria por no poder trasladarla a otro, tal como sucede en las minas, en los aprovechamientos de saltos de agua, etc., y donde no existe población importante, pero en las grandes ciudades los barrios obreros tienen graves inconvenientes desde todos los puntos de vista» ${ }^{58}$.

Sobre la cuestión obrera, el arquitecto Enrique María Repullés y Vargas intervino en Resumen de Arquitectura como cabeza visible de la SCA, tanto para tratar los temas relacionados con el trabajo: horario de ocho horas o descanso dominical, tan recurrentes en aquel momento tras la huelga general en Alemania, 1891-; como para debatir sobre la conveniencia de la creación de barrios obreros, aun considerando el tema molesto por carecer de interés y -con evidente intención política- contrario a los ideales de igualdad y democracia. Para la SCA, considerar conveniente construir barrios económicos diferenciados en las ciudades significaba optar por separar a la clase obrera del resto de la sociedad, por ello, justificaba su postura contraria en base a cinco principios fundamentales: la caridad, la moral y la higiene, por un lado; y la seguridad y la economía, por otro: «Se me dirá: es que lo que se desea es dar al obrero habitación sana, cómoda y barata, que le haga amar las delicias del hogar, que le aleje de la taberna, que le moralice... Utopía; nada de esto se consigue con la creación de los Barrios de obreros: por el contrario, no solo los creemos -y procuraremos demostrarlo-, contrarios a la caridad cristiana, a la moral y a la higiene, sino que pueden ser peligrosos a la sociedad y no proporcionan economía al operario» 59 .

Ejercer la caridad precisaba de la proximidad del obrero, para ayudarle, protegerle y remediar sus necesidades: «debemos conocerle, tenerle cerca de nosotros, viviendo en nuestras propias casas, (...) donde conocerá que las clases que cree sus enemigas le atienden y le socorren y que, por tanto, son sus amigas y protectoras» ${ }^{60}$. Recuperar la moral requería asimismo de esta proximidad, de la convivencia y el ejemplo. Y, en relación a la higiene: «En los Barrios de obreros, como habrán de ser económicos en su construcción para que resulten baratas las habitaciones, no podrán tener éstas gran desahogo y se producirá un hacinamiento muy propenso a la creación de focos insalubres, que pueden irradiar sus efectos al resto de la población por ser dificilísimo el aislamiento» ${ }^{61}$. Además, en otro orden de cuestiones, importaba mantener el orden social. Si el obrero se sentía expulsado de la ciudad y desconocía las mejores intenciones de las clases más favorecidas podrían generarse odios infundados. «Unidos en sus Barrios con tales ideas, se exacerbarán los ánimos y hasta se tramarán

56 Resumen de Arquitectura pretendía recuperar la línea iniciada en 1874 con la publicación de su primer Boletín, centrándose exclusivamente en temas de Arquitectura, como se hacía en Francia, Inglaterra, Italia, Alemania o Estados Unidos. Sociedad Central de Arquitectos, 1891b, p. 3.

57 Cerdá, 1867, p. 238.

58 Repullés, 1891, p. 34.

59 Repullés, 1891, p. 65.

60 Repullés, 1891, p. 65.

61 Repullés, 1891, p. 66. 
conspiraciones revolucionarias que atonten al orden público. Es, pues, un peligro social el Barrio obrero» ${ }^{62}$. ¿Cuál sería entonces el beneficio? Los terrenos que permitían la construcción de estos barrios se encontraban, por su menor coste, alejados de los centros de las poblaciones, obligando a recorrer grandes distancias. El perjuicio que suponía para el trabajo alejar de sus oficios a los operarios ya había sido un argumento ampliamente empleado, al igual que el de cuestionar el que representaba uno de los mayores atractivos de estas barriadas: la posibilidad de adquirir una vivienda en propiedad. En opinión de Repullés, nunca podría alcanzarse el equilibrio entre el capital que pudieran reunir los obreros durante un tiempo convenido y el necesario para construir casas saludables e higiénicas. Sin intervenir los poderes públicos, no se trataría más que de un negocio en manos de especuladores, por lo que se emplearían materiales pobres sin atenderse las reparaciones necesarias, adquiriendo al fin el obrero una casa en ruina, sin poder devolverle siquiera -por su elevado coste- las mínimas condiciones de habitabilidad. Así, la SCA mantenía su postura, todavía más conservadora -si cabe- que en la década anterior, reafirmándose en la conveniencia de mantener los sistemas mixtos de estratificación social: «El bello ideal sería una casa cuya planta baja se destinase a los industriales, el piso principal al aristócrata, el segundo al hombre de carrera o negocios, el tercero al empleado modesto y los interiores y sotabancos al operario. En contacto forzoso todos se conocerían y se estimarían (...) Esta manera de dar habitación al obrero es, sin duda, la más democrática, la más caritativa, la verdaderamente social. Así se conseguirá su moralización y su educación» ${ }^{63}$.

Sin embargo, consciente del beneficio que podría malograrse con los alquileres baratos, la SCA introdujo al discurso una consideración final que hasta el momento nunca había planteado, sorprendentemente para justificar, en cierto modo, la posible existencia de barriadas obreras y el desplazamiento de los operarios de los centros de las poblaciones. «Es evidente que en los extremos de las ciudades, donde el terreno está barato y donde no exige tanto el ornato público, abundarán más las casas de bajo alquiler, y aunque vendrían en algunos puntos a constituir como barriadas de obreros, siempre formarían parte y continuación de la población, constituyendo su organismo, no separados y designados con nombre especial, antipático para muchos y estigma para algunos» ${ }^{64}$. Con esta idea se desmontaban muchos de los argumentos defendidos por la SCA, llegando incluso a replantearse el objeto mismo del debate, ¿qué no era conveniente entonces?, ¿la identidad o autonomía que pudieran alcanzar estas barriadas? Evidentemente, nunca había interesado abordar el debate urbanístico del barrio obrero como modelo de crecimiento, los conflictos e intereses sociales, económicos, políticos, profesionales e incluso morales, habían acaparado desde su primer planteamiento cualquier atención.

Desde esta reflexión pueden explicarse anteriores y posteriores contradicciones de la SCA, como la defensa de la comentada construcción de Benalúa en Alicante -1884- o de la barriada obrera en el denominado Campo de artillería en La Coruña $-1893-{ }^{65}$, calificando estos barrios como ejemplos a imitar y animando a su construcción en otras poblaciones, aunque se criticara después el negocio de la especulación. Este comportamiento viene a confirmar el panorama descrito por Joaquín Casañ en su intervención como ponente de la CRS, refiriéndose a la construcción de casas para obreros en España -sin haber pasado de la esfera especulativa- en relación a otros países como Inglaterra, Francia, Bélgica o Italia: «Así es que cuando aquellas naciones tienen estudiado y realizado el pensamiento, desde 1858, nosotros 
estamos todavía en el período de incubación sobre la manera de realizar en el nuestro lo que en los demás países es un hecho pasado, ya no de moda, sino a la categoría de cosa juzgada, a hecho consumado» ${ }^{66}$.

Tras la divulgación del artículo de Repullés, también reproducido por el autor en su libro $E l$ obrero en la Sociedad ${ }^{67}$, la SCA no consideraría necesario volverse a pronunciar sobre el tema. Debidamente aclarada su postura, se iría desvinculando progresivamente del asunto y pasaría a ocuparse de otras cuestiones, principalmente relacionadas con la reforma interior de Madrid. Ni siquiera iniciativas tan relevantes como: la creación, en 1894, de la Compañía Madrileña de Urbanización, fundada por Soria y en la que también participaba Belmás, para la construcción de «barriadas cómodas, higiénicas y baratas» de acuerdo con la teoría de la Ciudad Lineal -planteada en 1882-; la fundación, en 1896, de la Ligue Française du Coin de Terre et du Foyer, por el abad Jules Lemire, consolidando la institución de los jardines obreros -iniciada en 1890 por Madame Hervieu en Sedán, Francia-; o la constitución, en 1899, de la Garden-City Association, fundada por Ebenezer Howard -quien acababa de publicar en 1898 su manifiesto Garden cities of tomorrow-, para desarrollar ciudades jardín; lograron atraer de nuevo la atención de la SCA ${ }^{68}$. De hecho, el Resumen de Arquitectura dejó de editarse, pasando a constituir en 1899 una misma publicación junto a la Revista de la Sociedad Central de Arquitectos, volviéndose a interesar en la organización de la profesión de Arquitecto sobre cualquier otra cuestión.

Por el contrario, el debate sobre la construcción de barrios obreros volvió a cobrar importancia en Europa en la transición del siglo XIX al XX. Una lectura del debate europeo, desde el prisma de las preocupaciones en España, puede seguirse a través de los informes que, sobre las sesiones de los Congresos Internacionales de Casas Baratas, elaboró el IRS; organismo creado en 1903 para preparar la legislación del trabajo y procurar, como su antecesora la CRS, la mejora y bienestar de las clases obreras. El IRS supuso la institucionalización de la política social del Estado ${ }^{69}$, se encargó de preparar las bases para un Proyecto de Ley de Casas para Obreros o Casas Baratas, valiosísimo documento publicado inicialmente en 1907, posteriormente ampliado en su segunda edición de 1910, que daría lugar, en 1911, a la primera Ley española de Casas Baratas. Por su parte, la SCA también redactó, en 1908, un informe sobre la construcción de casas baratas e higiénicas, si bien, centrado en las cuestiones relativas a la arquitectura y su estilo ${ }^{70}$.

\section{El debate en los Congresos Internacionales de Casas Baratas a través de los informes del Instituto de Reformas Sociales, 1897-1907}

Como se ha mencionado, el argumento de la localización y distribución espacial de la vivienda económica apareció siempre de soslayo en los primeros Congresos de Casas Baratas, su ordenación dentro o fuera de las ciudades consolidadas, su agrupación en barriadas más o menos dispersas o su integración en la urbanización general, no fueron temas de interés hasta

66 Casañ, 1890, p. 23-24.

67 Repullés, 1892.

68 Sobre la Ciudad Lineal, véase Soria, 1894. Sobre los Jardines Obreros, véase Leal, 1904. Sobre la Ciudad Jardín, véase Howard, 1902.

69 Presidencia del Consejo de Ministros, 1903. Ministerio de la Gobernación, 1903. El Reglamento del Instituto de Reformas Sociales asentó las bases para el desarrollo de la legislación sobre Casas Baratas. Véase Calle, 1997, p. 136.

70 Sambricio, 2004, p. 49. 
la celebración, en 1897, del cuarto Congreso de Bruselas. Como los anteriores Congresos, el de Bruselas también se centró en buscar respaldos para justificar las leyes que se iban aprobando, la cuestión de la intervención pública seguía siendo el primer tema convenido e impregnaba todos los debates, pero por primera vez incorporó un discurso paralelo, del que dejó constancia en sus informes el IRS.

\section{El cuarto Congreso de Bruselas (1897)}

De acuerdo con los informes del IRS, de una parte, resultó relevante la participación de Schnetzler -ponente suizo- en el debate central sobre la intervención del Estado, afirmando que éste debía «tender a facilitar la construcción de casitas, tipo Mulhouse o Suchard, o casas de tres o cuatro habitaciones, en las condiciones normales de coste y de rendimiento» ${ }^{71}$. El interés en citar estos referentes, tanto del tipo de casa como del modelo de organización suburbana, resultó más que elocuente, aun sin aludir de forma directa al tema de la construcción de barrios obreros. De otra parte, el segundo debate acordado: «Si en el caso de una expropiación de barriadas enteras en un Municipio convendría obligar al expropiante a reemplazar por nuevas habitaciones baratas las suprimidas a causa de la expropiación» ${ }^{72}$, tratándose además de la expropiación por zonas en los centros de las poblaciones, sirvió para introducir definitivamente el asunto.

Sobre la cuestión se presentaron dos trabajos contrapuestos. En la línea del discurso defendido por la SCA, Victor Bauvais -ponente belga, vicepresidente del Comité de Patronage des Habitations Ouvrières de Bruxelles Est-, criticó que la expropiación de los barrios obreros en los centros de las poblaciones tuviera que conllevar la expulsión de sus habitantes con el consecuente distanciamiento de sus lugares de trabajo y la formación de barrios de clase. Las habitaciones económicas expropiadas debían, en su opinión, reedificarse mejoradas en los mismos terrenos o suelos próximos, evitando su desaparición de los emplazamientos céntricos, una postura que compartieron tanto los participantes franceses como ingleses ${ }^{73}$. Charles Lucas -arquitecto del Conseil de la Société française des habitations à bon marchédenunció que la excesiva plusvalía de los terrenos expropiados propiciara el desalojo y la construcción de inmuebles de mayor renta. No debía permitirse por este motivo la expulsión de los obreros de las ciudades, sumándose al problema otras cuestiones de orden moralista: «los obreros que para llegar a su casa tienen que andar mucho, hacen, sobre todo cuando han cobrado, más estaciones de las que fueran deseables, con las consecuencias de disipación sabida ellos ni sus hijos pueden frecuentar los cursos industriales, cuyos establecimientos, lo mismo que las escuelas, pronto no habrá necesidad de subvencionar por lo mismo» ${ }^{74}$. Además, según Landrin -Conseiller généraux de la Seine-, el desplazamiento de los obreros del centro comportaría la caída del pequeño comercio al desaparecer su clientela habitual y no sería baladí el asunto del coste de los medios de transporte, ya que al tener que restarse del capital disponible para el alquiler comenzarían a proliferar alojamientos extramuros, como ya ocurría en la Banlieue de París, tan precarios como en las ciudades. El problema se evitaría «imponiendo la obligación de edificar a los que compren terrenos, de tal suerte, que una parte de las construcciones sea afecta a las habitaciones obreras» ${ }^{75}$. Al respecto, Owen Fleming arquitecto del London County Council- explicaba cómo en Inglaterra se había constatado que, con la expropiación, la población obrera, lejos de dispersarse, tendía a concentrarse en los

71 Instituto de Reformas Sociales, 1910, p. 101.

72 Instituto de Reformas Sociales, 1910, p. 100.

73 Instituto de Reformas Sociales, 1910, p. 112.

74 Instituto de Reformas Sociales, 1910, p. 115-116.

75 Instituto de Reformas Sociales, 1910, p. 114. 
lugares próximos, por lo que se exigía reedificar al menos en estos emplazamientos la mitad del volumen expropiado ${ }^{76}$.

Por contra, Emile Ver Hees -segundo ponente belga, director de l'Office du Travail de Belgique-, defendió la idea de que las nuevas viviendas económicas se ubicaran en «el barrio extremo» dejando para el comercio los centros de las poblaciones, por la razón que en sí misma justificaba la expropiación. Las ventajas de la higiene, entre otros beneficios, compensarían al obrero cualquier inconveniente. Así, «los barrios ricos y los pobres se separan por el juego de fuerzas naturales económicas», supuestamente en bien de la paz social. Incluso, las iniciativas que habían reconstruido las casas expropiadas en sus lugares iniciales, como la tan conocida del London County Council en Boundary Street, reforzaban esta idea al haberse desarrollado en barrios que no eran céntricos. Construir habitaciones baratas accesibles para los obreros en propiedad sin establecer un precio máximo para los terrenos no era factible y esta idea era impensable en los centros de las poblaciones por tener que renunciar a los constantes e importantes incrementos de valor generados en virtud de la oferta y la demanda ${ }^{77}$.

Entre ambos extremos y en la más absoluta ausencia de un debate urbanístico, muy pocas opiniones avanzaron hacia el pensamiento de que era necesaria cierta flexibilidad en la elección del emplazamiento de las nuevas habitaciones económicas, sin existir un sistema único válido para cualquier país o ciudad. Había, además, una gran variedad de habitaciones obreras construidas que considerar: antiguos grupos en el centro de las ciudades habiéndose desplazado las industrias que las originaron; las que constituían barrios que pertenecían a sociedades o patronos tan rechazados por los denominados moralistas; o casas aisladas propiedad de los mismos obreros. Con todo, los avances en pro de la cohesión social fueron escasos, si bien destacó la intervención del ingeniero belga el barón del Marmol quien, apoyándose en la idea de que «la aglomeración, que tiene tantas ventajas sociales -comercio, recreos, círculos de amistad-, es incompatible con un nuevo barrio embellecido», defendía que el obrero pudiera vivir donde quisiera, escogiendo su residencia por agrado o interés de su trabajo $^{78}$.

\section{El quinto Congreso de París (1900) y el sexto Congreso de Düsseldorf (1902)}

Recién inaugurando el siglo XX, se celebró en París -1900- el quinto Congreso de Casas Baratas, tratándose -en el punto séptimo- el tema de los jardines obreros, cuestión que en Francia ya había sido objeto de proyectos de Ley y que llamó la atención del IRS. El debate, desarrollado a partir del estudio del ponente Jules Angot des Rotours y la defensa que del mismo realizó Louis Riviére, concluyó con el respaldo unánime de los asistentes a favor de la idea de facilitar al obrero terrenos alrededor de su casa, incluso en los casos en que debieran situarse algo separados de la misma o se tratara de viviendas colectivas. Los jardines servían a un doble fin social: mejorar la condición económica de las familias por el cultivo de la tierra, sustituyendo «el socorro gratuito por el socorro en virtud de un trabajo», y contrarrestar los muchos atractivos insanos de las ciudades industriales, además de contribuir a la mejora de la higiene $^{79}$.

76 Instituto de Reformas Sociales, 1910, p. 115.

77 Instituto de Reformas Sociales, 1910, p. 113-114.

78 Instituto de Reformas Sociales, 1910, p. 114-115.

79 Instituto de Reformas Sociales, 1910, p. 131. 
Los jardines o huertos obreros se extendieron rápidamente, primero en Francia y Bélgica y después en Suiza y Alemania, adoptando diferentes formas de organización. Eran concesiones de superficie variable, de entre doscientos y setecientos metros cuadrados, gratuitas o económicas, establecidas por periodos o de forma vitalicia. En muchos casos, hasta llegaron a convertirse en propiedad de las familias propiciando incluso la construcción de casas. De algún modo, anticipaban el atractivo que después ofrecerían las ciudades jardín: acercar a los centros urbanos las ventajas del campo, los beneficios de vivir y trabajar en el medio rural para compensar la vida «artificial» de las ciudades industriales ${ }^{80} ;$ «....consiste en hacer, en cuanto se pueda, compatible con la residencia en la ciudad y con el trabajo de la fábrica, la estancia al aire libre y el trabajo de la tierra al obrero industrial. Ese es el objeto de los jardines obreros» ${ }^{81}$.

En los informes del IRS se destacaron asimismo otras cuestiones que apuntaban indirectamente a la conveniencia de los barrios obreros. En el debate central sobre la intervención del Estado, el ponente francés Rostand sugirió proporcionar los medios económicos y rápidos de circulación urbana que permitieran residir a las familias modestas en la periferia de las ciudades sin precisar tiempos excesivos para acceder al trabajo. En la cuestión de la movilidad urbana también insistió el ponente alemán Joseph Stübben proponiendo, entre otras medidas, para favorecer la construcción de habitaciones baratas, el trazado de nuevas calles en los alrededores y la instalación de tranvías que comunicaran estas periferias con los centros de las ciudades. En la propuesta concurrían dos circunstancias: por un lado, la dotación de infraestructuras y el acceso al crédito eran las bases fundamentales de la estrategia de intervención del Estado alemán para impulsar el desarrollo económico; y por otro lado, la calle se estaba planteando como una nueva estrategia de crecimiento y unidad de zonificación.

El factor suelo era especialmente determinante en las grandes ciudades industriales alemanas por su creciente concentración de personas y actividades. Las normativas de zonificación, dividiendo la ciudad en zonas por usos y densidades, habían constituido, desde la década de 1890, los instrumentos de control social y económico para hacer frente a los complejos problemas de la ciudad -bienestar, orden público, seguridad de las comunidades- y para ordenar su desarrollo -previendo una estructura lógica-. Sin embargo, los primeros esquemas de zonificación adoptados en franjas circulares y concéntricas, disminuyendo la densidad de la edificación del centro a la periferia, habían conseguido el efecto contrario al esperado: la separación de clases por niveles de renta, concentrando en la periferia a las masas obreras y proletarias, por el menor precio de los terrenos. Es cierto que el zoning, con carácter ideológico y funcional, asumía el principio de segregación, pero para lograr sus objetivos precisaba realizar una división más articulada.

La mayor difusión y reconocimiento del zoning se produjo en los primeros años 1900, cuando se inició una segunda fase de evolución del instrumento. Para poder tener en cuenta en la zonificación otros parámetros socioeconómicos además de las rentas, por iniciativa de las administraciones municipales y de otras organizaciones como los colegios profesionales, el colectivo de técnicos -arquitectos, ingenieros y urbanistas- llevó a cabo un intenso estudio de mercado interaccionando con todos los agentes participantes en la ciudad, públicos y privados: inmobiliarias, empresas constructoras, cooperativas de construcción y particulares. Se obtuvo así un cuadro preciso de la realidad de la sociedad que sirvió, en primer lugar, para el establecimiento de una serie de categorías socioeconómicas -clasificación de la población

80 Leal, 1904 , p. 337, 339-340 y 345.

81 Leal, 1904, p. 340. 
por renta, prestigio social, categoría profesional, jerarquía en el lugar de trabajo- y para la determinación de las necesidades de la vivienda para cada una de estas categorías correspondencia con una tipología edificatoria-; y en segundo lugar, para establecer posibles relaciones funcionales entre las distintas categorías, las agrupaciones sociales menos peligrosas para su ubicación -integración o separación- en el territorio. Esta experiencia de distribución de clases sociales en la ciudad afectó tanto a los edificios -tipologías edificatorias- y su organización espacial -formas de agrupación-, como a la dimensión y forma de las manzanas, a su parcelación, a la configuración de las calles -arboladas o no según categoría, a sus funciones, medidas- y, por tanto, a la creación de barrios enteros para las diferentes clases sociales.

La monotonía de estos barrios de clase, repitiéndose el mismo tipo de edificación por responder a una categoría social determinada, conllevó un nuevo debate paralelo que condujo a la variación de la escala de aplicación del zoning desde la escala del barrio a la escala de la calle, permitiendo así una mayor articulación y fraccionamiento de las zonas urbanas y en particular de las áreas residenciales. De este modo, diferentes categorías de calle podían combinarse en la configuración del barrio, definiendo con su trazado la estrategia de crecimiento y desarrollo de las diversas zonas urbanas. En este contexto tuvieron lugar los congresos de París y Düsseldorf, coincidiendo con el planteamiento inicial de esta nueva escala de aplicación del zoning que se extendería hasta el inicio de la Primera Guerra Mundial.

En consecuencia, el valor del suelo ya no se establecería por áreas sino por la unidad de zonificación que constituía la calle, permitiendo así un mayor ajuste de este valor con la combinación de diferentes tipologías de explotación. Si bien, en todos los casos se concebía imposible que el obrero pudiera ser propietario en la ciudad, cuestión en la que insistió especialmente el sexto Congreso de Düsseldorf -el Wohnungs Kongress o Congreso de la Habitación, no sólo de la habitación obrera-. En este Congreso se debatió precisamente, y en primer lugar, sobre la influencia del valor del suelo, tanto en los gastos de construcción como en el precio de los alquileres de las casas ${ }^{82}$.

La zonificación por calles en Alemania tuvo una gran acogida por permitir ajustar los valores del suelo, pero también por conferir una mayor flexibilidad a las normativas para ajustarse a las necesidades, cambios y exigencias particulares, actuando sobre zonas más pequeñas y diferenciadas en base a una más amplia gama de variables de uso y características de la edificación. De este modo, el zoning pasó a constituir, cada vez más, un instrumento de proyección y construcción de la ciudad ${ }^{83}$.

Paralelamente, defendiendo la construcción de barrios en los alrededores de las ciudades y en la búsqueda del modelo más conveniente, en 1902 se fundó en Alemania la Deutsche Gartenstadt-Gesellschaft, asociación que -transcurrida una década- sobresaldría como mejor discípula de la propuesta de Howard. A Alemania le seguiría Francia. El Musée Social que había sido fundado en 1894 comenzó a interesarse por el modelo de ciudad jardín en 1903, coincidiendo con la creación del IRS ${ }^{84}$ y el primer congreso de la Garden-City Association. El abogado Georges Benoît-Lévy se encargó de recabar información y terminó fundando la

82 Instituto de Reformas Sociales, 1910, p. 134-136. Respecto al Congreso de Düsseldorf, el problema en Alemania no era sólo la vivienda obrera, sino la carencia de habitaciones en general, véase al respecto p. 32. 83 Mancuso, 1980. Piccinato, 1993.

84 Los miembros del Instituto de Reformas Sociales estuvieron estrechamente ligados al Musée Social de París y ayudaron en la creación de colonias que llegaron a proclamarse ciudades jardín. Véase Guerrand, 2000-2001. 
Association des cités-jardins de France, en la que actuó como secretario. En el año siguiente 1904- publicó La cité-jardin. Actuó asimismo como ponente sobre la cuestión en el séptimo Congreso de Casas Baratas de Lieja -1905-, el primero que planteó el tema de la ciudad jardín $^{85}$.

\section{Del séptimo Congreso de Lieja (1905) al octavo Congreso de Londres (1907)}

Si bien en el Congreso de Lieja se debatió -en su cuarta cuestión- sobre las «Reglas para establecer planos de conjunto de barrios nuevos de manera que se consiga la lotificación más conveniente de los terrenos, ya sea para transformar aglomeraciones existentes o para el desarrollo de nuevos terrenos. Las ciudades jardín» ${ }^{86}$, en los informes del IRS no se destacó el asunto como relevante, incluso llegó a suprimirse cualquier comentario. A excepción de las referencias publicadas por Soria en su revista La Ciudad Lineal, en 1899 y $1904^{87}$, la propuesta de la ciudad jardín todavía no había sido difundida en España. La cité-jardin de Benoît-Lévy fue probablemente el primer libro sobre el tema conocido en el país y no tenemos constancia de que así fuera antes de 1911. Sería después, en el octavo Congreso de Londres -1907-, cuando el IRS comenzaría a interesarse por el tema ${ }^{88}$. Moret Predergast, Cabello Lapiedra y Mendizábal, fueron los delegados por España, los mismos que ya habían sido encargados en el anterior Congreso de Lieja ${ }^{89}$.

La ciudad jardín se impuso en Londres como única solución al problema de la vivienda y así lo percibió el IRS. En opinión del presidente de la First Garden City Company Limited, Aneurin Williams, sólo existían dos posibles soluciones para resolver el problema de la aglomeración en las grandes ciudades: construir nuevos arrabales o trasladar a otros lugares parte de la población. Sólo una de estas soluciones era beneficiosa, por ello se había construido la ciudad jardín de Letchworth al Norte de Londres, con capacidad para albergar 32.000 habitantes. Ya en la sesión inaugural del Congreso, John Burns, presidente del Local Government Board, había insistido en la relación entre el problema de la habitación y el abandono de los campos; y en las siguientes sesiones, se habían destacado las ventajas del sistema de casas aisladas individuales -cottage-, para una o dos familias en propiedad o arrendamiento, frente al de casas de alquiler para varias familias -block- o de cuartelesobreros. Este último tema volvería a tratarse en el noveno Congreso de Viena -1910- ${ }^{90}$.

Se trataron asimismo otros muchos temas que afectaban ya no sólo a la construcción de barrios sino a la creación de nuevas ciudades modelo: de la problemática para obtener terrenos, de la planificación urbanística -hasta de la distribución de los solares-, de la regulación de la edificación, de la movilidad y medios de comunicación -desde los centros de las ciudades a los barrios extremos y entre las ciudades y el campo, mediante trenes o tranvías-. Incluso, la última sesión se dedicó al estudio de las habitaciones rurales, de las

85 Ramos, 2008.

86 Véase la ponencia introductoria realizada por Georges Benoît-Lévy — 1905—, reproducida en la revista Ciudades. Benoît-Lévy, 2000-2001.

87 Véase Soria, 2000-2001a y 2000-2001b —reproducciones de 1899 y 1904 respectivamente_, coincidiendo con las ediciones de Howard: To-morrow: A Peaceful Path to Real Reform, 1898; reimpresa como Garden Cities of To-Morrow, 1902.

88 Instituto de Reformas Sociales, 1908, p. 11-14.

89 Como apunta Castrillo, 2000-2001, p. 129 y ss., el Instituto de Reformas Sociales fue probablemente la primera entidad española que contactó directamente con el círculo fundacional de la ciudad jardín, a través del Congreso de Londres. Para conocer las principales ponencias en Londres, véanse las reproducciones de 1907 Williams, 2000-2001; Howard, 2000-2001; y Unwin, 2000-2001.

90 Instituto de Reformas Sociales, 1910, p. 152-153 y 155. 
aldeas y ciudades del campo, al fomento de la vida rural, de la pequeña propiedad y el pequeño cultivo -smallholding-. De acuerdo con los informes del IRS, se trataba de contrarrestar la atracción que sobre la población del campo ejercían las grandes ciudades. Se abría, así, una nueva etapa para el Urbanismo. La planificación urbanística iría adquiriendo progresiva importancia y el discurso internacional sobre las ciudades jardín, con sus diversas interpretaciones más o menos acertadas, terminaría absorbiendo los primigenios debates sobre barrios obreros ${ }^{91}$.

\section{Conclusiones}

La denuncia del problema de la vivienda, sobre todo de la escasez de habitaciones económicas y de sus precarias condiciones higiénicas, no se produjo en España de forma tardía. Al contrario, atendiendo al ritmo en que fueron introduciéndose en el país los procesos industriales y los cambios sociales originados por los nuevos sistemas de producción -con cierto retraso respecto de otros países europeos-, se constata una acertada anticipación en la figura del ingeniero Ildefonso Cerdá. Cerdá no analizó el estado de la vivienda de forma aislada sino en su contexto urbano, como parte del estudio general de la construcción de las ciudades. Este hecho propició la posibilidad de considerar, tempranamente en España mediado el siglo XIX-, la opción de construir barrios obreros, además de la oportunidad de conocer los primeros modelos ensayados en los países vecinos más industrializados. Otros autores, sobre todo vinculados con el asociacionismo obrero, sucedieron a Cerdá difundiendo las ventajas de estos barrios, si bien, la Exposición Universal de París de 1867 evidenció el desinterés general por el asunto frente a la intensa actividad desarrollada en los países extranjeros. La Exposición de París supone en nuestro estudio un punto de inflexión por garantizar el conocimiento en España de lo que ocurría en Europa, circunstancia que nos permite comprobar -y seguir haciéndolo en adelante- la absoluta indiferencia de los organismos oficiales y otras asociaciones relacionadas; únicamente siguieron produciéndose aportaciones de diversos autores individualmente sin llegar a plantearse la idea de un debate colectivo.

El rechazo a discutir sobre la conveniencia o no de construir barrios obreros se mantuvo hasta la celebración, en 1881, del primer Congreso Nacional de Arquitectos de Madrid -durante más de dos décadas desde que Cerdá abordara el asunto-. Por presiones sociales insoslayables, la Sociedad Central de Arquitectos -en adelante SCA- decidió -como organizadora- erigirse protagonista del debate e incluirlo en su programa. Aunque, como muchos arquitectos advirtieron, sólo se trató de una maniobra política sin intención de llegar a concretar ningún debate urbanístico. Estratégicamente, iniciar la discusión permitió a la SCA reorientar el tema, controlar y lentificar su desarrollo. De este modo, posicionándose en defensa de la ciudad tradicional, la SCA lideró la oposición frente a cualquier forma de crecimiento que pudiera comprometer, como en el caso de los barrios obreros, el orden social y económico establecido. Desde este posicionamiento, su influencia en el desarrollo del debate puede resumirse en cinco intervenciones:

El arquitecto Álvarez Capra fue el primer portavoz de la SCA en el Congreso de Madrid. Su tesis consistió en mantener la idea de ciudad como espacio mixto de integración social y el empleo de tipologías edilicias rígidas -y obsoletas- basadas en la diferenciación vertical de clases, evitando la aparición de áreas separadas conflictivas para el orden público y la higiene.

91 Instituto de Reformas Sociales, 1910, p. 151 y 154. 
Así, el trasfondo ideológico, paternalista y de cierta superioridad moral impregnó desde el principio el discurso de la SCA, posibilitando el control y contención de las clases obreras así como el mantenimiento de los beneficios económicos de la industria de la construcción en la ciudad.

La segunda intervención se produjo un año después -1882- de forma anónima, a través de la Revista de la Sociedad Central de Arquitectos, forzada de nuevo por la presión social y su repercusión en la prensa. Para justificar su postura, la SCA desarrolló dos nuevos argumentos: la importancia de mantener la proximidad entre las viviendas y los puestos de trabajo, descartando la construcción de barrios periféricos; y la lógica de rechazar propuestas utópicas, como la idea de imaginar al obrero propietario en barrios económicos sin existir terrenos para soportar tal economía. En cualquier caso, es sobre todo relevante descubrir la primera concesión en el -en apariencia- inamovible discurso de la SCA: comenzaron a aceptarse, además de las construcciones mixtas, las casas de vecindad -edificaciones especiales segregadas en la ciudad-, a pesar de separar las clases sociales en contra de los argumentos defendidos por la SCA.

Transcurrido un año se produjo la tercera intervención -1883-, con el único propósito de reivindicar para los arquitectos sus competencias y el derecho a pertenecer a la serie de comisiones que, por iniciativa del Estado, se crearon para estudiar las necesidades de las clases obreras. La cuarta intervención se produjo siete años después -1890- y con la misma intención, cuando fue reorganizada la Comisión de Reformas Sociales -en adelante CRS-. La SCA inició entonces una nueva estrategia, tratar de erigirse en representación de los obreros de la construcción, lo que evidenció claramente su indiferencia por el verdadero problema de la vivienda y su distribución espacial.

En la siguiente etapa con Resumen de Arquitectura, el arquitecto Repullés y Vargas intervino como portavoz de la SCA, llevando el discurso de Álvarez Capra al extremo. Comenzaron a admitirse los barrios industriales, pero siguieron denunciándose los inconvenientes de los barrios obreros en las ciudades. La tesis de Repullés fue repetitiva, consistió en denunciar la pretensión de separar la clase obrera del resto de la sociedad desarrollando cinco argumentos ya empleados por la SCA: la caridad y la moral, que precisaban de la proximidad, la convivencia y el ejemplo; la seguridad y la higiene -reñida con la economía-, por constituir posibles núcleos de desorden e infección; y la economía, por los problemas de movilidad generados al ocupar terrenos periféricos -más baratos y con menores exigencias- y por las promesas de propiedad insostenibles. Sin intervenir los poderes públicos, en opinión de la SCA, los barrios obreros sólo alentaban la especulación. No obstante, Repullés introdujo una elocuente consideración final, una segunda concesión en el discurso de la SCA, que no puede servir mejor de conclusión a nuestro estudio. Paradójicamente a pesar de su razonamiento, consciente de que en las periferias resultaba más rentable construir, asumió excepcionalmente la existencia de barriadas económicas y el desplazamiento de la población obrera del centro de las ciudades, conformándose con advertir que se entendieran estos barrios como continuación de las poblaciones y no separados o con autonomía propia. Tras esta quinta intervención -1891-, capaz de desmontar cualquiera de sus argumentos anteriores, la SCA no volvió a considerar oportuno pronunciarse sobre el tema. Había retrasado el necesario y verdadero debate urbanístico durante una década.

Un discurso paralelo, aunque con menor repercusión, se había iniciado también en el primer Congreso de Madrid -1881-, provocando la ruptura interna de la misma SCA. Desde el principio, los defensores de los barrios obreros estuvieron muy cerca del modelo de ciudad 
jardín, aunque todavía no se hubiera teorizado su concepto. Los arquitectos Mariano Belmás, elogiando las agrupaciones de unifamiliares económicas distribuidas en las poblaciones, y Arturo Soria, con su innovadora propuesta de Ciudad Lineal como modelo alternativo no sólo de crecimiento sino de cohesión social -1882-, son prueba de que en España no ocurrió de modo diferente. Resulta esclarecedor que la SCA obviara sistemáticamente las propuestas de ambos colaboradores, incluso tras llevarse a la práctica alguna de sus iniciativas; si bien, tampoco llegó a reconocer los Jardines obreros planteados por Lemire o las Garden Cities ideadas por Howard. La SCA fue apartándose del debate conforme avanzó la política social del Estado en España y resurgió el tema de los barrios obreros en Europa. En el último discurso de Repullés se advertían estas influencias: de la CRS -que comenzaba a difundir sus estudios-, al destacar los temas de la separación de clases, la propiedad obrera o la distribución espacial de la vivienda como forma de control; y de los primeros Congresos Internacionales de Casas Baratas, al introducir la cuestión de la intervención del Estado, de los barrios industriales o de la expulsión de los operarios de las ciudades por la expropiación de barriadas enteras; en ambos casos muy a propósito de la influencia de la experiencia alemana. Comenzaba una nueva etapa, de cierre para un debate español interno: la conveniencia o no de construir barrios obreros; y de apertura a una forma distinta de hacer en Europa: las ciudades jardín que, con mayor o menor calado y/o acierto, serían interpretadas. En los informes del Instituto de Reformas Sociales -IRS- sobre los Congresos de Casas Baratas, se constata el interés repentino que las ciudades jardín despertaron en España, pasando de su omisión en Lieja -1905- a su reconocimiento en Londres -1907-, a pesar de ya haberse tratado el tema en fecha temprana -en el Congreso de Madrid en 1881 y a propuesta de Belmás-. La ciudad jardín, desde sus primeras concepciones hasta su definitiva formulación teórica, abre y «cierra» pues el debate de los barrios obreros en España, iniciando un nuevo curso donde la planificación urbanística adquirirá absoluta importancia.

\section{Bibliografía}

ALONSO PEREIRA, J.R. Mariano Belmás, arquitecto de la Ciudad Lineal. Q: Revista del Consejo Superior de los Colegios de Arquitectos de España. Madrid: CSCAE, 1982, nº 58, p. 46-57.

BARREIRO PEREIRA, P. Casas Baratas. La vivienda social en Madrid.1900-1939. Madrid: Comisión de Cultura del Colegio Oficial de Arquitectos de Madrid, 1992.

BELMÁS ESTRADA, M. Las construcciones económicas del Sistema Belmás, bajo los puntos de vista social, constructivo y económico: conferencia dada en el Fomento de las Artes, el día 16 de abril de 1881. Madrid: Imprenta y Estereotipia de Aribau y Ca, 1881.

BELMÁS ESTRADA, M. Medios para dar solución al problema de las construcciones económicas: conferencia dada en el Fomento de las Artes, el día 15 de abril de 1882. Madrid: Establecimiento Tipográfico de Sucesores de Rivadeneyra, 1882.

BELMÁS ESTRADA, M. Construcciones económicas y casas para obreros. Madrid: Imprenta de Enrique Teodoro, 1883.

BENOÎT-LÉVY, G. VII ${ }^{\text {me }}$ Congrès international des habitations à bon marché. Rapport présenté au nom de l'Association des Cités-Jardins de France. 1905. Ciudades. Revista del Instituto Universitario de Urbanística de la Universidad de Valladolid. Valladolid: Universidad de Valladolid, 2000-2001, no 6, p. 159-170. 
BLAT PIZARRO, J. Vivienda obrera y crecimiento urbano, (Valencia 1856-1936). Valencia: Generalitat Valenciana y Colegio Oficial de Arquitectos de la Comunidad Valenciana, 2000.

BUJ BUJ, A. La cuestión urbana en los informes de la Comisión de Reformas Sociales. Scripta Vetera, Edición Electrónica de trabajos publicados sobre Geografía y Ciencias Sociales. En línea. Reproducido de CAPEL SÁEZ, H., LÓPEZ PIÑERO, J.M. y PARDO TOMÁS J. Ciencia e ideología en la ciudad (II). I Coloquio Interdepartamental. Valencia, 1991.Valencia: Generalitat Valenciana, 1994, p. 73-86. <http://www.ub.edu/geocrit/sv-32.htm>. 18 de octubre de 2014.

CACHAVERA, H. y LAMPÉREZ, V. Exposición al Excmo. Sr. Ministro de la Gobernación. Revista de la Sociedad Central de Arquitectos. Madrid: Sociedad Central de Arquitectos, 31 de mayo de 1890, p. 194-195.

CALLE VELASCO, M.D. La Comisión de Reformas Sociales: de la represión al análisis de la conflictividad social. Studia histórica. Historia contemporánea. Salamanca: Universidad de Salamanca, 1984, $\mathrm{n}^{\circ}$ 2, p. 13-40.

CALlE VELASCO, M.D. Sobre los orígenes del Estado social en España. Ayer. Revista de Historia Contemporánea. Madrid: Asociación de Historia Contemporánea, 1997, no 25, p. 127- 150.

CAPEL SÁEZ, H. Capitalismo y morfología urbana en España. $4^{\mathrm{a}}$ ed. Barcelona: Los libros de la Frontera, 1983.

CAPEL SÁEZ, H. Geografía Humana y Ciencias Sociales. Una perspectiva histórica. Barcelona: Editorial Montesinos, 1987.

CAPEL SÁEZ, H. La Morfología de las ciudades. Tomo I, Sociedad, cultura y paisaje urbano. Barcelona: Ediciones del Serbal, 2002.

CAPEL SÁEZ, H. La Morfología de las ciudades. Tomo II, Aedes facere: técnica cultura y clase social en la construcción de edificios. Barcelona: Ediciones del Serbal, 2005.

CAPEL SÁEZ, H. La Morfología de las ciudades. Tomo III, Agentes urbanos y mercado inmobiliario. Barcelona: Ediciones del Serbal, 2013.

CASAÑ ALEGRE, J. Casas para obreros. Memoria que sobre su estudio y medios de plantearlas en España redactó como ponente de la Comisión de reformas sociales en el Ateneo Complutense su presidente Joaquín Casañ y Alegre. $4^{\mathrm{a}}$ ed. Valencia: Imprenta de Francisco Vives Mora, 1890.

CASTRILLO ROMÓN, M.A. Introducción: el "evangelio" de la ciudad-jardín, algunas notas sobre su difusión en España. Ciudades. Revista del Instituto Universitario de Urbanística de la Universidad de Valladolid. Valladolid: Universidad de Valladolid, 2000-2001, nº 6, p. 127-149.

CASTRILLO ROMÓN, M.A. Reformismo, vivienda y ciudad. Orígenes y desarrollo del debate en España 1850-1920. Colección Arquitectura y Urbanismo 38. Valladolid: Universidad de Valladolid, 2001. 
CASTRILLO ROMÓN, M.A. Influencias europeas sobre la "Ley de Casas Baratas" de 1911: el referente de la "Loi des Habitations à Bon Marché" de 1894. Cuadernos de investigación urbanística. Madrid: Universidad Politécnica de Madrid, noviembre de 2003, nº 36, p. 5-52.

CASTRO SERRANO, J. La cabaña de la señorita Maurey. España en París. Revista de la Exposición Universal de 1867. Madrid: Librería de Durán, 30 de agosto de 1867, nº, p. 122-123.

CERDÁ SUÑER, I. Teoría de la construcción de las ciudades aplicada al Proyecto de Reforma y Ensanche de Barcelona. 1859. In Teoría de la construcción de las ciudades: Cerdá y Barcelona, vol. 1. Madrid: Instituto Nacional de la Administración Pública y Ajuntament de Barcelona, 1991.

CERDÁ SUÑER, I. Teoría general de la urbanización y aplicación de sus principios y doctrinas a la Reforma y Ensanche de Barcelona. Tomo I. Madrid: Imprenta Española, 1867. Ed. facsímil. Madrid: Instituto de Estudios Fiscales, 1968.

COLEGIO OFICIAL DE ARQUITECTOS DE MADRID. De la Sociedad Central de Arquitectos al Colegio de Arquitectos de Madrid: un largo camino. En línea. Madrid: Colegio Oficial de Arquitectos de Madrid, octubre de 2006 - 2007. <http://www.coam.org/pls/portal/docs/PAGE/COAM/COAM_PUBLICACIONES/html/75coam.html> . 18 de octubre de 2014.

CONCHA AlCALDE, J. Reformas municipales. Revista de la Sociedad Central de Arquitectos. Madrid: Sociedad Central de Arquitectos, 20 de septiembre de 1882, p. 154-156; 20 de octubre de 1882, p. 180-183; 20 de noviembre de 1882, p. 201-203; y 30 de enero de 1883, p. 21-24.

CONSTRUCTORA DEL NUEVO CARABANCHEL. El Nuevo Carabanchel y la Constructora del Nuevo Carabanchel. Madrid: Establecimiento Tipográfico Sucesores de Rivadeneyra, 1895.

COSTA MARTÍNEZ, J. Instituciones económicas para obreros. Las habitaciones de alquiler barato en la Exposición Universal de París en 1867. Biblioteca Costa, vol. XV. Tortosa: Casa Editorial Monclús, 1918.

GARRIDO TORTOSA, F. Historia de las asociaciones obreras en Europa o las clases trabajadoras regeneradas por la asociación. Tomo II. Barcelona: Imprenta y Librería de Salvador Manero, 1864.

GRANELL, E. y RAMON, A. Col·legi d'Arquitectes de Catalunya, 1874-1962. Barcelona: Col·legi d'Arquitectes de Catalunya, 2012.

GUERRAND, R. Sobre los orígenes del movimiento de las ciudades-jardines en Europa. Ciudades. Revista del Instituto Universitario de Urbanística de la Universidad de Valladolid. Valladolid: Universidad de Valladolid, 2000-2001, nº 6, p. 17-20.

HALL, P. Ciudades del mañana: Historia del urbanismo en el siglo XX. Colección La estrella polar. Barcelona: Ediciones del Serbal, 1996.

HOWARD, E. Garden cities of to-morrow -being the second edition of "to-morrow: a peaceful path to real reform"-. London: Swan Sonnenschein \& Co., Ltd., 1902. 
HOWARD, E. Les garden cities et l'entassement de domiciles. 1907. Ciudades. Revista del Instituto Universitario de Urbanística de la Universidad de Valladolid. Valladolid: Universidad de Valladolid, 2000-2001, nº 6, p. 175-178.

INSTITUTO DE REFORMAS SOCIALES. Congresos Sociales en 1907. Madrid: Imprenta de la sucesora de M. Minuesa de los Ríos, 1908.

INSTITUTO DE REFORMAS SOCIALES. Preparación de las bases para un proyecto de ley de casas para obreros, Casas baratas. $2^{\text {a }}$ ed. 2 Tomos. Madrid: Imprenta de la sucesora de M. Minuesa de los Ríos, 1910.

ISAC, A. Ideal arquitectónico y alojamiento obrero en el I Congreso Nacional de Arquitectos de 1881. Q: Revista del Consejo Superior de los Colegios de Arquitectos de España. Madrid: CSCAE, 1982, $\mathrm{n}^{\circ}$ 58, p. 34-46.

LASHERAS PEÑA, A.B. España en París. La imagen nacional en las exposiciones universales, 1855-1900. Tesis doctoral dirigida por Luis Sazatornil Ruiz. Santander: Universidad de Cantabria, 2009.

LAVALLÉE, T. et al. Le diable à Paris: Paris et les parisiens. Vol. 2. París: Typographie Lacrampe et Comp. J. Hetzel, 1845-1846.

LÁZARO DE DIEGO, J.B. El estilo moderno. Revista de la Sociedad Central de Arquitectos. Madrid: Sociedad Central de Arquitectos, 30 de agosto de 1882, p. 140-142; 10 de septiembre de 1882, p. $146-$ 149; y 30 de noviembre de 1882, p. 210-211.

LEAL RAMOS, L. La obra de los jardines obreros. Revista católica de las cuestiones sociales. Madrid: junio de 1904, nº 114, p. 336-349.

MANCUSO, F. Las experiencias del zoning. Colección Ciencia Urbanística. Barcelona: Editorial Gustavo Gili, 1980.

MARTÍNEZ DE SAS, M.T. Los comienzos de un problema secular: la política sobre la vivienda obrera y los alquileres en los primeros socialistas españoles. Scripta Nova, Revista Electrónica de Geografía y Ciencias Sociales. En línea. Barcelona: Universidad de Barcelona, 1 de agosto de 2005, vol. IX, no 194 (22). <http://www.ub.edu/geocrit/sn/sn-194-22.htm>. 18 de octubre de 2014.

MINISTERIO DE LA GOBERNACIÓN. Real Orden de 9 de septiembre de 1853. Gaceta de Madrid. Madrid: Imprenta Nacional, 13 de septiembre de 1853, nº 256, p. 2.

MINISTERIO DE LA GOBERNACIÓN. Real Decreto de 7 de diciembre de 1883. Gaceta de Madrid. Madrid: Imprenta Nacional, 10 de diciembre de 1883, nº 344, p. 761-763.

MINISTERIO DE LA GOBERNACIÓN. Real Decreto de 13 de mayo de 1890. Gaceta de Madrid. Madrid: Imprenta Nacional, 14 de mayo de 1890, n 134, p. 426.

MINISTERIO DE LA GOBERNACIÓN. Real Decreto de 15 de agosto de 1903. Gaceta de Madrid. Madrid: Imprenta Nacional, 18 de agosto de 1903, nº 230, p. 1970-1973. 
NAVASCUÉS PALACIO, P. La Ciudad Lineal de Arturo Soria. Villa de Madrid. Madrid: Ayuntamiento de Madrid, 1969, n²8, p. 49-58.

NAVASCUÉS PALACIO, P. Ciudad Lineal. In AA.VV. Madrid. Tomo III. Madrid: Espasa Calpe, 1979, p. 1101-1120.

PÉREZ DEL HOYO, R. y GUTIÉRREZ MOZO, M.E. Primeras políticas de vivienda en España y su influencia en la evolución de la tipología residencial: el caso de Benalúa (1883-1956). Revista INVI. Santiago de Chile: Instituto de la Vivienda y Universidad de Chile, agosto de 2013, vol. 28, $\mathrm{n}^{\mathrm{o}} 78$, p. 221-255.

PICCINATO, G. La construcción de la urbanística: Alemania, 1871-1914. Barcelona: Oikos-Tau, 1993.

PRESIDENCIA DEL CONSEJO DE MINISTROS. Real Decreto de 23 de abril de 1903. Gaceta de Madrid. Madrid: Imprenta Nacional, 30 de abril de 1903, nº 120, p. 371-372.

PRIEGO FERNÁNDEZ DEL CAMPO, C. et al. Dibujos de arquitectura madrileña de los siglos XIX y XX. Madrid: Museo de Historia de Madrid, 2010.

RAMÓN, F. Los precursores, capítulo primero de "Ideologías Urbanísticas". Ciudades. Revista del Instituto Universitario de Urbanística de la Universidad de Valladolid. Valladolid: Universidad de Valladolid, 1993, n 1, p. 131-150.

RAMOS GOROSTIZA, J.L. El descontento frente a la ciudad industrial: reformismo social y "ciudad jardín” en España, 1900-1923. Revista de Historia Industrial. Barcelona: Universitat de Barcelona, 2008, nº37, p. 85-122.

REBOLLEDO PALMA, J.A. Casas para obreros o económicas. Madrid: Imprenta de la viuda e hijos de Galiano, 1872.

REPUlLÉS VARGAS, E.M. La Exposición de Minería. Revista de la Sociedad Central de Arquitectos. Madrid: Sociedad Central de Arquitectos, 30 de diciembre de 1883, p. 281-284.

REPULLÉS VARGAS, E.M. Operarios y obreros. Resumen de Arquitectura. Madrid: Sociedad Central de Arquitectos, 31 de mayo de 1891, p. 33-34; 31 de julio de 1891, p. 53-55; y 30 de septiembre de 1891, p. 65-67.

REPULLÉS VARGAS, E.M. El obrero en la sociedad. Madrid: Imprenta y Lit. de los Huérfanos, 1892.

SAMBRICIO, C. De la Ciudad Lineal a la Ciudad Jardín. Sobre la difusión en España de los supuestos urbanísticos a comienzos del siglo. Ciudad y Territorio. Estudios territoriales. Madrid: Ministerio de Fomento, octubre de 1992, no 94, p. 147-159.

SAMBRICIO, C. Un siglo de vivienda social (1903-2003). Madrid: Editorial Nerea, 2003.

SAMBRICIO, C. Madrid, vivienda y urbanismo: 1900-1960. Colección Arquitectura 28. Madrid: Akal, 2004.

SHUBERT, A. A Social History of Modern Spain. Londres: Unwin Hyman Ltd., 1990. 
SOCIEDAD CENTRAL DE ARQUITECTOS. Revista de la Sociedad Central de Arquitectos. Madrid: Sociedad Central de Arquitectos, 1882, 1883a, 1884-1890 y 1891a-1898a.

SOCIEDAD CENTRAL DE ARQUITECTOS. Sesiones del Congreso Nacional de Arquitectos celebrado en Madrid en mayo de 1881 por iniciativa de la Sociedad Central y documentos referentes al mismo. Madrid: Establecimiento Tipográfico de Gregorio Juste, $1883 \mathrm{~b}$.

SOCIEDAD CENTRAL DE ARQUITECTOS. Resumen de Arquitectura. Madrid: Sociedad Central de Arquitectos, 1891b-1898b.

SOCIEDAD CENTRAL DE ARQUITECTOS. Resumen de Arquitectura. Revista de la Sociedad Central de Arquitectos. Madrid: Sociedad Central de Arquitectos, 1899-1900.

SORIA MATA, A. Madrid remendado y Madrid nuevo. Diario El Progreso. Madrid, 6 de marzo de 1882.

SORIA MATA, A. La ciudad lineal. Diario El Progreso. Madrid, 10 de abril de 1882.

SORIA MATA, A. La cuestión social y la Ciudad Lineal. Diario El Progreso. Madrid, 5 de marzo de 1883.

SORIA MATA, A. Compañía Madrileña de Urbanización. Conferencia dada en el Ateneo Científico y Literario de Madrid por D. Arturo Soria y Mata el día 14 de mayo de 1894 acerca de la nueva arquitectura de las ciudades. Madrid: Establecimiento Tipográfico Sucesores de Rivadeneyra, 1894.

SORIA MATA, A. La ciudad ideal. The Garden City. Ejecución de un pensamiento de Reclus. Agosto de 1899. Ciudades. Revista del Instituto Universitario de Urbanística de la Universidad de Valladolid. Valladolid: Universidad de Valladolid, 2000-2001a, nº 6, p. 151-154.

SORIA MATA, A. Garden-City. La Cité-Jardin. 1904. Ciudades. Revista del Instituto Universitario de Urbanística de la Universidad de Valladolid. Valladolid: Universidad de Valladolid, 2000-2001b, $\mathrm{n}^{\mathrm{o}}$ 6, p. 155-157.

TATJER, M. La vivienda obrera en España de los siglos XIX y XX: de la promoción privada a la promoción pública (1853-1975). Scripta Nova, Revista Electrónica de Geografía y Ciencias Sociales. En línea. Barcelona: Universidad de Barcelona, 1 de agosto de 2005, vol. IX, n ${ }^{\circ} 194$ (23). <http://www.ub.edu/geocrit/sn/sn-194-23.htm>. 18 de octubre de 2014.

TERÁN, F. Revisión de la Ciudad Lineal: Arturo Soria. Arquitectura. Madrid: Colegio Oficial de Arquitectos de Madrid, 1964, nº72, p. 3-20.

TERÁN, F. La Ciudad Lineal, antecedentes de un urbanismo actual. Cuadernos Ciencia Nueva. Madrid: Ciencia Nueva, 1968.

TEXIER, E.A. Tableau de Paris. Vol. 1. París: Paulin et Le Chevalier, 1852-1853.

UNWIN, R. Town planning. 1907. Ciudades. Revista del Instituto Universitario de Urbanística de la Universidad de Valladolid. Valladolid: Universidad de Valladolid, 2000-2001, nº 6, p. 179-182. 
WILLIAMS, A. La cité jardin en rapport avec la decentralization industrielle. 1907. Ciudades. Revista del Instituto Universitario de Urbanística de la Universidad de Valladolid. Valladolid: Universidad de Valladolid, 2000-2001, nº 6, p. 171-173.

YESTE NAVARRO, I. Una aproximación al tema de la vivienda obrera: la barriada Rusiñol en Zaragoza. Artigrama, Revista del Departamento de Historia del Arte. Zaragoza: Universidad de Zaragoza, 2003, nº 18, p. 549-572.

(C) Copyright: Raquel Pérez del Hoyo, 2016.

(c) Copyright:Clara García-Mayor, 2016

(C) Copyright:Leticia Serrano Estrada, 2016

(C) Copyright Scripta Nova, 2016.

Ficha bibliográfica:

PÉREZ DEL HOYO, Raquel; GARCÍA-MAYOR, Clara; SERRANO ESTRADA, Leticia. La construcción de barrios obreros: una aproximación al debate urbanístico en España, 1881-1907. Scripta Nova. Revista Electrónica de Geografía y Ciencias Sociales. [En línea]. Barcelona: Universidad de Barcelona, 15 de octubre de 2016, vol. XX, no 546. <http://www.ub.es/geocrit/sn/sn-546.pdf>. ISSN: 1138-9788. 